\title{
The Role of Carbon Quantum Dots in Organic Photovoltaics: A Short Overview
}

\author{
Barbara Vercelli (D)
}

check for

updates

Citation: Vercelli, B. The Role of Carbon Quantum Dots in Organic Photovoltaics: A Short Overview. Coatings 2021, 11, 232. https:// doi.org/10.3390/coatings11020232

Academic Editor: Alicia de Andrés

Received: 18 January 2021

Accepted: 10 February 2021

Published: 15 February 2021

Publisher's Note: MDPI stays neutral with regard to jurisdictional claims in published maps and institutional affiliations.

Copyright: (C) 2021 by the author. Licensee MDPI, Basel, Switzerland. This article is an open access article distributed under the terms and conditions of the Creative Commons Attribution (CC BY) license (https:// creativecommons.org/licenses/by/ $4.0 /)$.
Istituto di Chimica della Materia Condensata e di Tecnologie per l'Energia, Consiglio Nazionale delle Ricerche, ICMATE-CNR, Via Cozzi, 53, 20125 Milano, Italy; barbara.vercelli@cnr.it

\begin{abstract}
Carbon quantum dots (CDs) are a new class of fluorescent carbonaceous nanomaterials that were casually discovered in 2004. Since then, they have become object of great interest in the scientific community because of their peculiar optical properties (e.g., size-dependent and excitation wavelength-dependent fluorescence), which make them very similar to the well-known semiconductor quantum dots and suitable for application in photovoltaic devices (PVs). In fact, with appropriate structural engineering, it is possible to modulate CDs photoluminescence properties, band gap, and energy levels in order to realize the band matching suitable to enable the desired directional flow of charge carriers within the PV device architecture in which they are implanted. Considering the latest developments, in the present short review, the employment of CDs in organic photovoltaic devices (OPVs) will be summarized, in order to study the role played by these nanomaterials in the improvement of the performances of the devices. After a first brief summary of the strategies of structural engineering of CDs and the effects on their optical properties, the attention will be devoted to the recent highlights of CDs application in organic solar cells (OSCs) and in dye sensitized solar cells (DSSCs), in order to guide the users towards the full exploitation of the use of these nanomaterials in such OPV devices.
\end{abstract}

Keywords: carbon quantum dots; organic solar cells; dye-sensitized solar cells

\section{Introduction}

The sun provides about 120,000 terawatts to the earth's surface, which amounts to 6000 times the present rate of the world's energy consumption [1]. Solar energy represents a clean, sustainable, abundant, and inexhaustible energy resource which could be exploited and converted. Solar cells are electrical devices that convert light into electricity through the photovoltaic (PV) effect; they consists of a p-n junction, characterized by the creation of an electric current upon the illumination of the material. Research efforts devoted to the conversion of solar energy into electrical energy through solar cells have led to the development of variable categories of solar cells, like silicon solar cells, thin-film solar cells, multi-junction solar cells, quantum dot solar cells, organic/polymer solar cells, etc. Among them, organic photovoltaic devices (OPVs) have become a case of study when compared to silicon and other PV technologies because of their light weight, semitransparency, flexibility, and tunable colors. Furthermore, recent studies reported power conversion efficiencies of ca $14 \%$ in single solar cells and ca $17 \%$ in tandem ones [2]. Besides these advantages and the growing interest, also, in the field of mobile phone charges [3], these devices still suffer for the limit of being realized using materials that are considered toxic and hazardous in the recent vision of a sustainable economy based on solar energy. In fact, they usually employ inorganic semiconductor quantum dots, which contain heavy metals, small organic molecules that need hazardous solvents to be processed, or dye-sensitizers that are based on molecular complexes containing heavy metals. Within this scenario, fluorescent carbon quantum dots (CDs) could be considered a low cost and sustainable alternative to these materials [4]. CDs are new class of carbonbased nanomaterials (different from fullerenes, graphenes, carbon nanotubes, and other 
carbon allotropes) which were casually discovered by $\mathrm{Xu}$ et al. [5]. Since then, they have become an object of great research interest in the materials science community [6-8]. In fact, compared to conventional inorganic semiconductor-based quantum dots, they exhibit peculiar features, like high photostability, nontoxicity, water solubility, and low-cost [9-18]; see Figure 1.

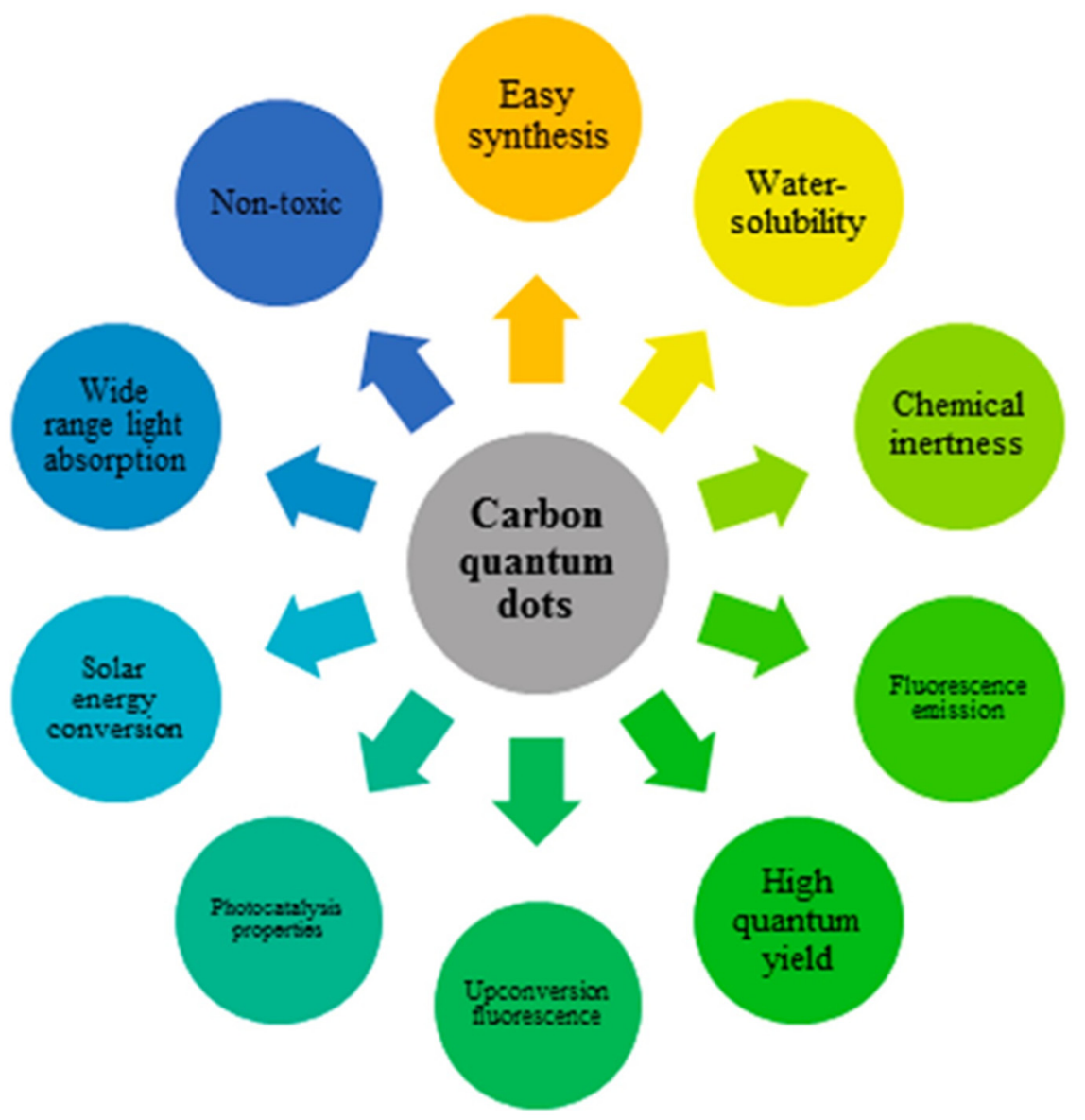

Figure 1. Carbon quantum dots (CDs) properties. Reprinted with the permission of Reference [19]. Copyright 2020 Elsevier Ltd.

Their synthesis methods are cheap and sustainable [20] and usually are divided into two main categories: top-down and bottom-up methods [21]. Top-down strategies are characterized by the "breaking" of larger carbon structures, like graphite, graphene, carbon nanotubes, carbon black, coal, etc., into smaller nano-sized ones under harsh and strong conditions, such as arc-discharging, laser ablation, electrochemical etching, or chemical oxidation. On the other side, bottom-up strategies are based on the preparation of CDs starting from small molecules or polymer precursors under relatively facile and mild conditions, like hydrothermal treatment, ultrasonic reaction, microwave-assisted pyrolysis, supported routes, etc. CDs obtained by top-down methods are characterized by high crystallinity and intact structures [22-24], while the ones obtained by bottom-up methods occasionally present an amorphous carbon core and abundant doping sites and surface functional groups $[25,26]$. The employment of CDs in photovoltaic (PV) devices was favored by their peculiar optical properties (e.g., size-dependent and excitation wavelength-dependent fluorescence), which make then very similar to the well-known semiconductor quantum dots (sQDs) $[27,28]$. In fact, with appropriate structural engineering, it is possible to modulate CDs photoluminescence properties, band gap, and energy levels, in order to realize the band matching suitable to enable the desired directional flow of charge carriers within the PV device architecture in which they are implanted. For example, Yan et al. [29] performed 
theoretical studies on graphene quantum dots (GQDs) and estimated that their highest occupied molecular orbital (HOMO) and lowest occupied molecular orbital (LUMO) energy levels were $5.3 \mathrm{eV}$ and $3.8 \mathrm{eV}$, respectively, below the vacuum level. These values enable them to show that CDs can be employed as sensitizers in dye sensitized solar cells (DSSCs) because they are able to inject electrons across the "dye" / semiconductor interface into the $\mathrm{TiO}_{2}$, and then, consequently, they could be reduced through an electron donation from the electrolyte $\left(\mathrm{I}_{3}{ }^{-} / \mathrm{I}^{-}\right)[29]$. Starting from these results, many other experimental studies were performed to show suitable band matching [30-33] and efficient charge separation/electron injection capabilities [28,33-35] for CDs, not only within sensitized metal oxide-based devices [26-39] but also within other device architectures, like Bulk Heterojunction (BJH) organic solar cells (OSCs) [40-43]; see Scheme 1.

\section{Sensitized Metal Oxides}

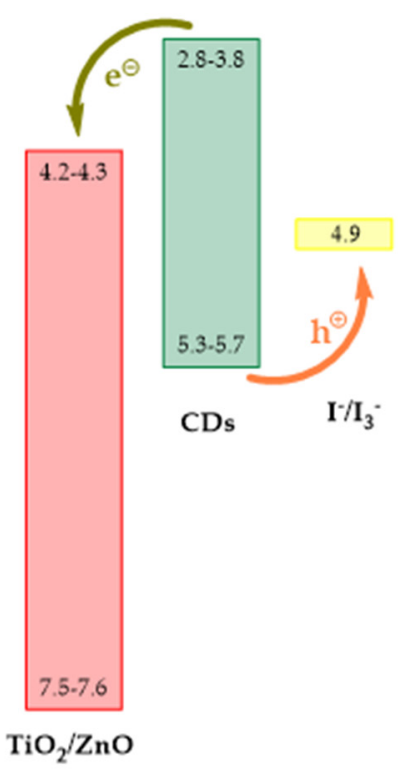

BHJ Electron Acceptors

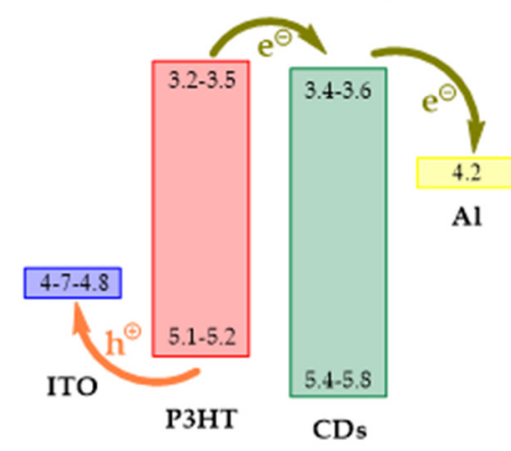

Scheme 1. Band-gap matching for CDs as sensitizer in sensitized metal oxides and as electron acceptors in bulk heterojunction (BHJ) solar cells. Values were pooled from Refs. [29,36,42,43].

From the above considerations, the present short review will firstly show how it is possible to tailor the optical properties of CDs (band gap and energy levels) through simple synthetic and post-synthetic strategies, in order to obtain the band alignment suited for applications in solar cells architectures. Then, the roles covered by CDs in OPV devices will be presented mainly focusing on organic solar cells (OSCs) and dye sensitized (DSSCs).

\section{Structure Engineering and Optical Properties}

In general, CDs are known as surface-passivated small carbon nanoparticles (with the size less than $10 \mathrm{~nm}$ ) that are brightly fluorescent [44]. Valcárcel's group [45] reported a rational and systematic classification of CDs based on their nature, crystalline structure, and quantum confinement. From this classification results that amorphous quasi-spherical nanodots which lack quantum confinement are considered to be carbon nanodots (CNDs), while spherical quantum dots with quantum confinement and crystalline structures are referred to as carbon quantum dots (CQDs), and the $\pi$-conjugated single sheets are referred to as graphene quantum dots (GQDs) (Scheme 2A). 
A
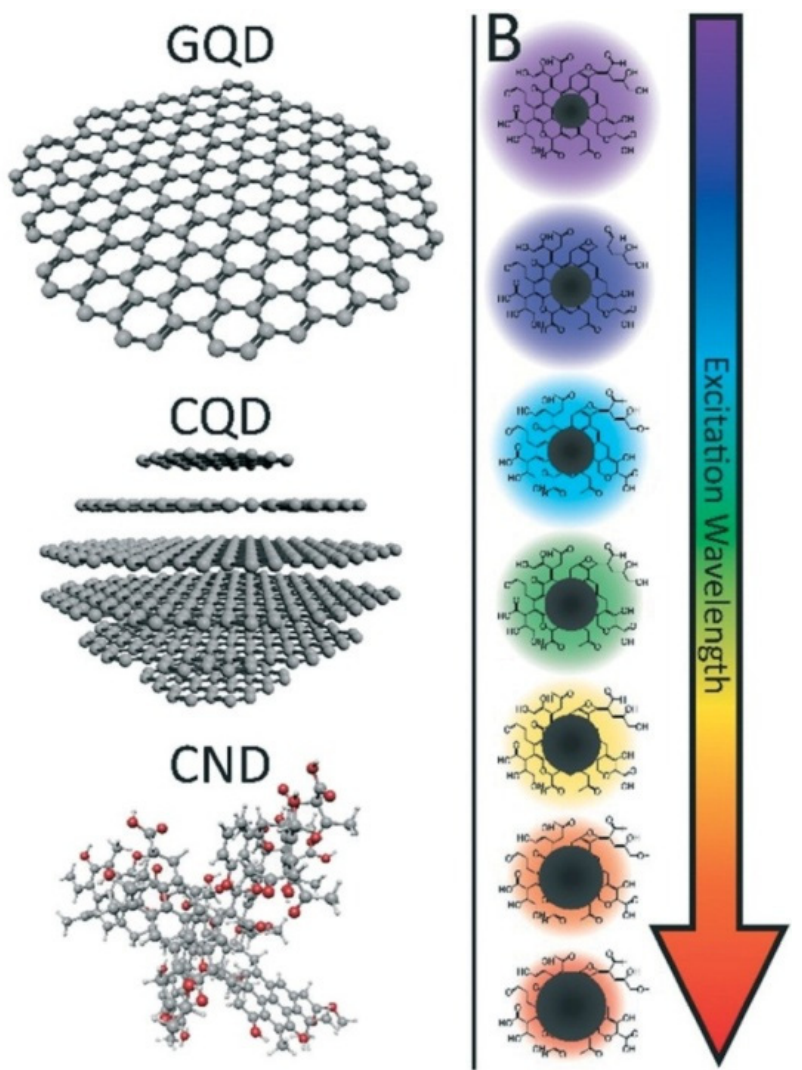

Scheme 2. (A) Representative structures of single-layer graphene quantum dots (GQDs), multilayered carbon quantum dots (CQDs) and amorphous carbon nanodots (CNDs). (B) Representation of commonly observed fluorescence of these materials. Reprinted with the permission of Reference [46]. Copyright 2017 The Royal Society of Chemistry.

In some literature, "carbon quantum dots", which are more accurately referred to as CNDs, are not well defined because of the absence of the classical quantum confinement effect $[44,47]$. In general, the most appealing characteristic of CDs is photoluminescence (PL) [48-50]. The PL of CDs is quantitatively expressed by the value of the emission quantum yield (QY), which is affected by the synthetic routes and by the employed precursors. Generally, CDs produced by top-down strategies present relatively low QY compared with the ones obtained by bottom-up routes, although specific precursors and technologic conditions should be taken into account. In the most reported works, the PL profile of CDs is broad and depends on the excitation, i.e., the emission peak position and intensity are both affected by the excitation wavelength. In the first reported works, the emission peak of CDs is mostly located at the blue- or green-light region, while recent studies report the synthesis strategies of CDs that emit in the red and near infrared region [51-53]. Although there are many studies devoted to its origin, the mechanism of PL emission of CDs still remains a mystery and object of debate. At present, there are three main viewpoints for the PL origin of CDs: (1) surface-state emission, which is determined by the hybridization of the carbon backbone and connected chemical groups [54]; (2) core-state emission (quantum confinement), which is induced by perfect carbon crystals with less defects and modified groups; and (3) molecular fluorescence, which is induced by fluorescent impurities, since the byproducts generated during CDs synthesis mainly contribute to the fluorescence emission. Theoretically, the PL behavior and QY of CDs can be affected by their particle size and their surface states, i.e., as the size of the dot increases, the emission wavelength red-shifts, and the fluorescence intensity decreases. Furthermore, PL intensity can also be controlled by heteroatom doping and/or variation in surface functionality (Scheme 2B) [55-59]. Within this scenario, Chen et al. [60] employed density functional 
theory (DFT) and time-dependent density functional theory (TDDFT) to study the influence of size and shape of GQDs on the band gap and PL properties. Their results show that the fluorescence of GQDs shifts from deep UV to near infrared by increasing their size (Figure 2A). In particular, if the size of GQDs is varied from $0.89 \mathrm{~nm}$ to $1.80 \mathrm{~nm}$, their emission covers the whole visible light spectrum $(400-700 \mathrm{~nm})$. They also showed that the quantum confinement characteristics of the GQDs varied with their edge configurations. As Figure 2B shows, armchair edges widen the band gap of GQDs because the localized states are scattered in the structure-core, while GQDs with similar size but with zig-zag edges have a relatively narrow band gap because the localized states are pushed to the edge sites.

(A)

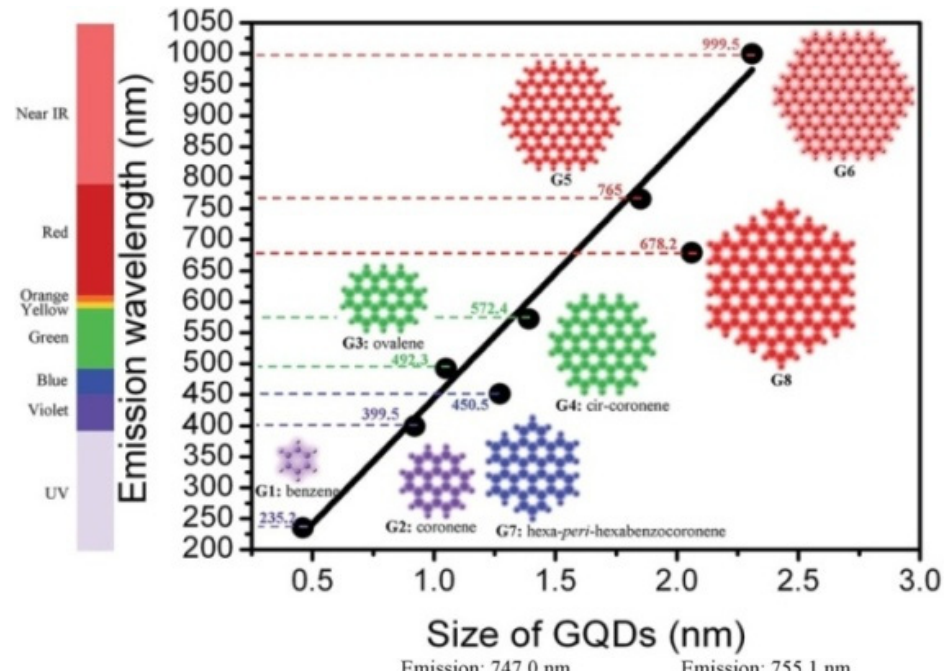

(a)

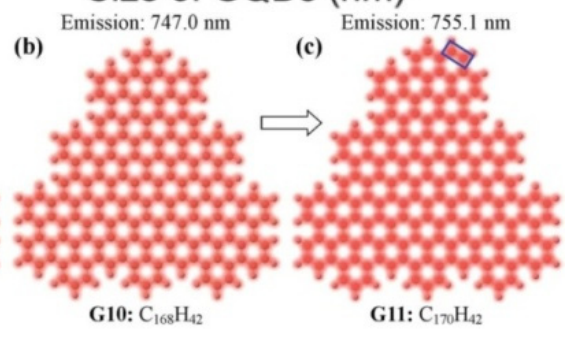

(B)
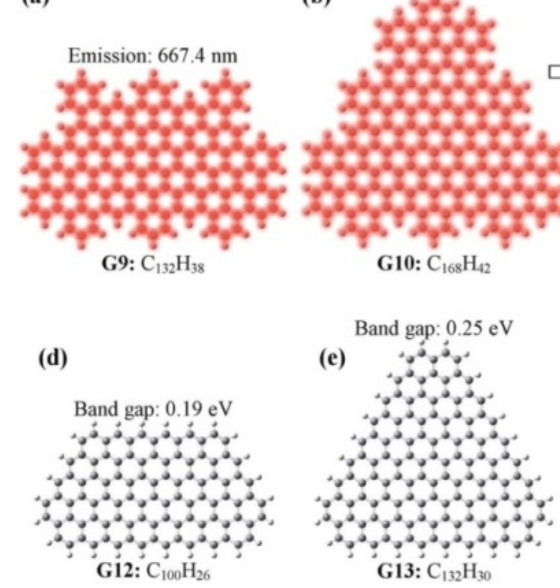

Figure 2. (A) Calculated emission wavelength $(\mathrm{nm})$ using the time-dependent density functional (TDDFT) method in vacuum as a function of the diameter of GQDs. (B) Structure of pristine (a) armchair-edged GQD $\left(\mathrm{C}_{132} \mathrm{H}_{38}\right)$, (b) armchair-edged GQD $\left(\mathrm{C}_{168} \mathrm{H}_{42}\right)$, (c) armchair-edged GQD $\left(\mathrm{C}_{170} \mathrm{H}_{42}\right)$, formed by inserting two additional carbons (marked by blue rectangle) on $\mathrm{C}_{168} \mathrm{H}_{42}$ GQD, (d) zigzag-edged GQD $\left(\mathrm{C}_{100} \mathrm{H}_{256}\right)$, and (e) zigzag-edged GQD $\left(\mathrm{C}_{132} \mathrm{H}_{30}\right)$. Reprinted with the permission of Reference [60]. Copyright 2019 The Royal Society of Chemistry.

The size and crystallinity of CDs can also be affected by the synthetic routes and the process conditions. For example, Hu et al. [61] employed the "bijective approach" to prepare controlled size CDs starting from single-chain polymeric nanoparticles, i.e., the amount of enediyne moiety in the linear polymer precursors was controlled in order to obtain narrowly distributed and size-tunable CDs. In this way, the authors showed that, starting from the three batches of linear polymers with the enediyne moieties of 266, 42, and 35 per polymer chain, it was possible to obtain CDs with average diameter of $4.5 \mathrm{~nm}$, 
$2.1 \mathrm{~nm}$, and $2.0 \mathrm{~nm}$, respectively. In another work, Pang et al. [62] reported that the size of CDs can be controlled by the electrochemical etching of carbon fibers at different applied potentials. They showed that, at applied potentials of $0.5 \mathrm{~V}, 1.5 \mathrm{~V}$, and $2.5 \mathrm{~V}$, the average diameter of the CDs was $3.3 \mathrm{~nm}, 2.7 \mathrm{~nm}$, and $2.2 \mathrm{~nm}$, respectively. In addition, post-synthesis treatments, like dialysis [63], centrifugation [64], ultra-filtration [22,65], gel electrophoresis [66], and column chromatography $[67,68]$, could be successfully employed to obtain purified and size-tunable CDs. The anion-exchange high performance liquid chromatography was employed by Colon et al. [68] to obtain fraction of CDs with different particle size distributions (average diameters of $7.1 \mathrm{~nm}, 9.4 \mathrm{~nm}, 10.1 \mathrm{~nm}$, and $14.0 \mathrm{~nm}$ ) starting from the as-made CDs mixture. In addition, surface modification and passivation can deeply influence CDs PL properties and energy gaps. Even more, in some CDs samples without surface passivation $[69,70]$, there are no detectable PL values. Various modification agents, including small molecules and polymers, have been widely used. Tetsuka et al. [71] synthetized GQDs functionalized with amino groups through the mild hydrothermal treatment of graphene oxide in ammonia solution. The obtained samples presented a higher $\mathrm{N} / \mathrm{C}$ ratio and the possibility of tuning their PL emission from violet to yellow through the control of primary amine functionalization. Starting from these encouraging results, they employed precursors containing different nitrogen-based groups to study their influence on the energy levels and gaps of the obtained GQDs (Figure 3) [72]. They found that the HOMO and LUMO levels of GQDs are continuously tuned by the different nitrogen moieties because of the resonance of their orbitals with the graphitic cores of GQDs. In particular, as Figure 3 shows, GQDS functionalized with o-phenylenediamine (OPD-GQDs), diaminonaphthalene (DAN-GQDs), azo (Azo-GQDs), or p-methyl red (pMR-GQDs) present lower HOMO energy levels, while the ones modified with primary (NH2-GQDs) or dimethyl amine (NMe2-GQDs) show higher and degenerate HOMO levels.

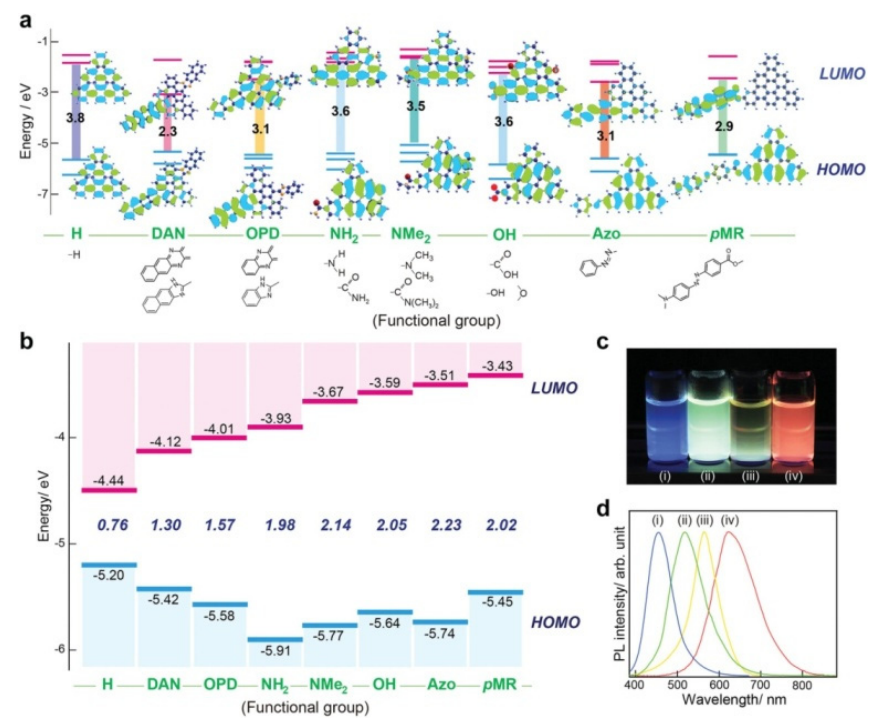

Figure 3. Energy levels and photoluminescence for nitrogen-functionalized graphene quantum dots (NGQDs). (a) Predicted energy level diagrams for graphene with different functional groups: ab initio calculations were performed at the B3LYP/6$31+G(p, d)$ level of theory using the Gaussian 09 package. Schematic illustrations show the chemical structures used for theoretical calculations. The isosurface presents the highest occupied molecular orbital (HOMO) and the lowest unoccupied molecular orbital (LUMO). (b) Measured energy level diagram for NGQDs. It is noteworthy that the mismatch between the predicted energy levels and the measured ones arises from the difference in the size of NGQDs and the quantity of nitrogenous functional groups. (c) Photoluminescence (PL) image of NGQDs in aqueous solution excited using a UV lamp (365 nm): (i) GQDS functionalized with azo (Azo-GQDs); (ii) NH2-GQDs; (iii) GQDS functionalized with ophenylenediamine (OPD-GQDs); and (iv) GQDS functionalized with diaminonaphthalene (DAN-GQDs). (d) Corresponding normalized PL spectra (excited at $380 \mathrm{~nm}$ ) from aqueous dispersions of NGQDs. Reprinted with the permission of Reference [72]. Copyright 2011 The Royal Society of Chemistry. 
It was also reported that $\mathrm{CDs}$ obtained through oxidative approaches, like nitric acid treatment, electrochemical etching, etc., present oxygen-containing functional groups on their surface which could be easily subjected to post-synthesis reduction treatments with consequent variation of their PL properties. In particular, it was observed that, by treating with $\mathrm{NaBH}_{4} \mathrm{CDs}$ obtained from the oxidative cutting of graphene oxide, their green emission in the oxidized state turned into blue in the reduced one with an improvement of their QY (Figure 4) [73]. The phenomenon was also proved to be reversible, and the reduced blue-emitting CDs were re-oxidized to the green-emitting ones for several cycles. Zhang and co-workers [74] suggested that the reduction treatment causes the partial transformation of the oxygen-containing species (mainly carbonyl and epoxy groups) present on CDs surface into hydroxyl groups. In fact, in their opinion, these oxygencontaining species in the "oxidized-form" of CDs induce a plenty of disordered states the $\mathrm{n}-\pi^{*}$ gap that causes a broad PL-emission peaked at longer wavelengths. The reductive agent treatment $\left(\mathrm{NaBH}_{4}\right)$ causes a partial decrease of theses disorder-induced states because of the formation of graphenol topological defects.

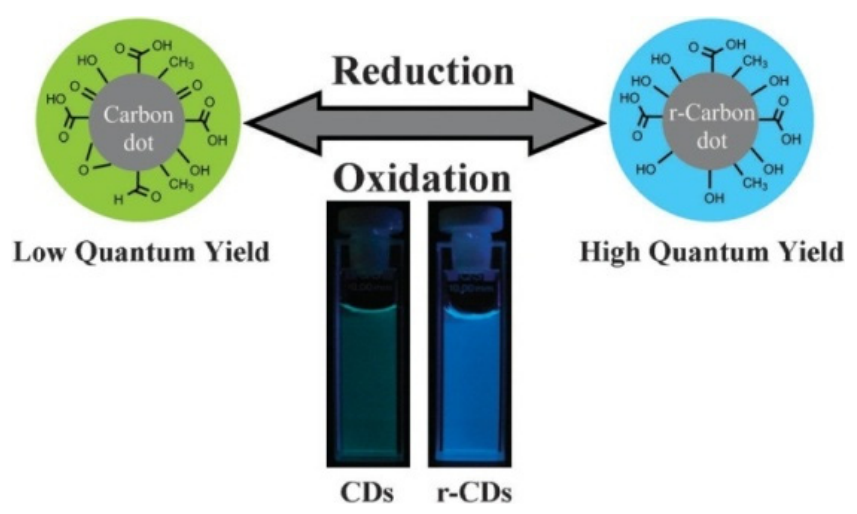

Figure 4. Graphical representation of the synthesis of reduced state carbon dots with blue luminescence from original carbon dots. Inset: photographs of aqueous solutions of the CDs (left) and the r-CDs (right) obtained under UV light $(360 \mathrm{~nm})$. Reprinted with the permission of Reference [73]. Copyright 2011 The Royal Society of Chemistry.

Mandal et al. [75] showed that it is possible to modulate the electronic structure of GQDs by both their size control and porphyrin functionalization. In particular, their results exhibit that the HOMO is controlled by the porphyrin molecules, while the LUMO is controlled by GQDs size. On the other hand, Prato et al. [76] improved the microwave synthesis of CDs starting from arginine and ethylenediamine with the addition of several commercially available quinones. They showed that the oxidation and reduction potentials of the obtained CDs could be tuned to energetically match different systems (Figure 5). Another strategy to tune the PL properties of CDs is the doping with etheroatoms. To this end, the work of Saavedra et al. [77] is interesting, where the effect of electron-deficient (boron atom) and electron-rich (nitrogen-atom) dopants on the band gaps and PL emission of GQDs were studied. They synthesized three different types of GQDs with similar sizes, chemical compositions and defects: undoped GQDs (UGQDs), boron-doped GQDs (BGQDs), and nitrogen-doped GQDs (NGQDs).

They combined spectroscopic characterizations and theoretical models to show that, in comparison with UGQDs, the BGQDs exhibited a red-shifted PL emission, while the NGQDs a blue-shifted one, as shown in Figure 6. They suggest that, in BGQDs, the empty orbital provided by the boron atom to the graphitic $\pi$ system causes a decrease of the electron density of the HOMO level with a consequent increase of the level. On the other hand, the lone electron pair provided by pyridinic nitrogens to the occupied $\pi$ orbitals in NGQDs causes a decrease of the HOMO level and widening of the band gap. 


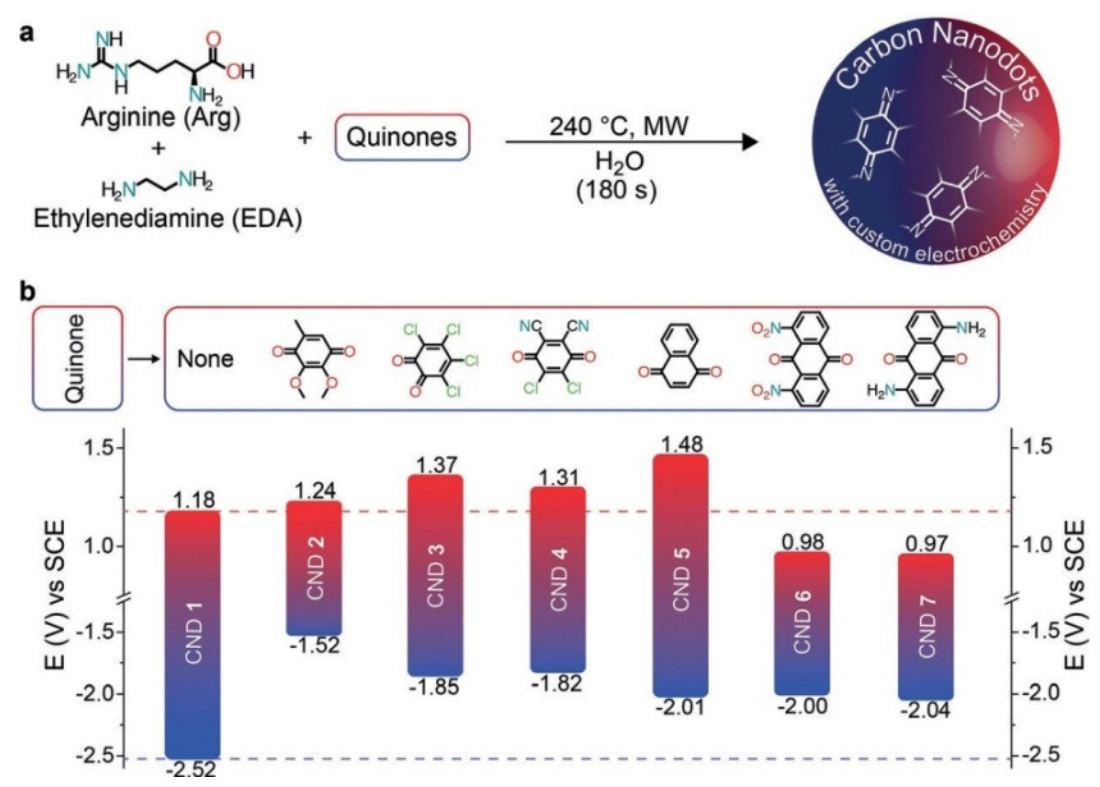

Figure 5. (a) Bottom-up synthesis of the CNDs. (b) Redox potentials of the CNDs (with the structures of the corresponding starting quinones employed as precursors). Reprinted with the permission of Reference [76]. Copyright 2018 Wiley-VCH Verlag GmbH \& Co. KGaA, Weinheim.

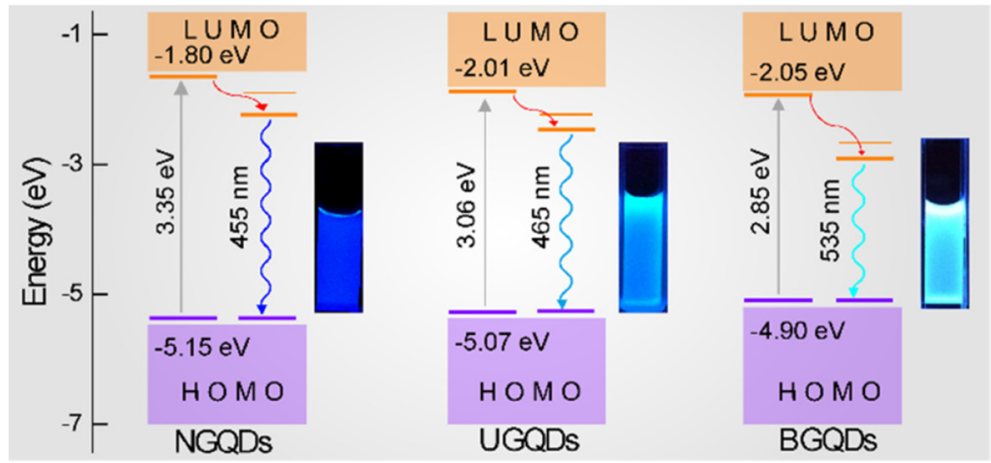

Figure 6. Experimentally measured HOMO and LUMO energy levels for nitrogen-doped GQDs (NGQDs), undoped GQDs (UGQDs), and boron-doped GQDs (BGQDs) and their emission wavelengths. Reprinted with the permission of Reference [77]. Copyright 2018 American Chemical Society.

Wang et al. [57] showed that different absorption and emission behaviors of CDs can be induced by the different types and position of the nitrogen doping atoms. In particular, they suggested that the doping in the core of the honey-comb matrix of CDs causes nonfluorescent mid-states which block the transition channel of the photo-excited electrons, while the doping at the edges of the CDs graphitic structure increases the photo-excited electrons in the emission transition channel, enhancing the probability of radiation transition and the PL intensity. Finally, it was also reported that the graphitic nitrogen atoms are supposed to generate midgap states within the HOMO-LUMO gap of CDs, causing the red-shifting of their absorption and PL-emission [78].

The theoretical and the experimental studies reported in this section clearly show how it is possible to tailor the optical properties of CDs through simple modifications of the synthetic strategies and/or suitable post-synthetic treatments, which enable the control of their size, crystallinity, surface functional groups, and doping etheroatoms. These features makes CDs good candidates for application as components in PV devices. In fact, the possibility to tune the band gap, and consequently the energy levels, of CDs enables the suitable energetical alignments that matches with the PV device architectures in which they 
are implanted. In the following section, the employment of CDs in OPVs, like OSCs and DSSCs, will be reported, highlighting the multiple roles they can cover in the realization of this kind of devices.

\section{Organic Photovoltaics (OPVs)}

Literature reports two recent review works dealing with both the applications of CDs in photocatalytic energy conversion [79] and with the role played by CDs in different PV devices [46]. The present section will be mainly devoted to Bulk Heterojunction (BJH) Organic Solar Cells (OSCs) and Dye Sensitized Solar Cells (DSSCs). These devices are considered promising for the next generation solar cells and have become object of great attention. In general, OSCs are usually known either as polymer solar cells (PSCs) or small molecules solar cells (SMSCs). They can be produced on large scale by the roll-to-roll process and are characterized by the flexibility and the low-cost of the device. On the other hand, DSSCs can be fabricated through manufacturing techniques starting from easily available materials. They are characterized by flexibility, conformability, transparency, excellent lowlight level or indoor light performance, and suitability for building-integrated photovoltaics (BIPV). The following sections will show how the employment of suitable designed CDs may improve the performances of these PV devices, compared with normally employed materials.

\subsection{Bulk Heterojunction (BHJ) Organic Solar Cells}

In a typical bulk heterojunction (BHJ) organic Solar Cells (OSCs) architecture, a BJH film is interposed in the layers between an electron-donating material (typically p-type conjugated polymers) and an electron-accepting material (typically n-type fullerene derivatives); see Scheme 3A.

A

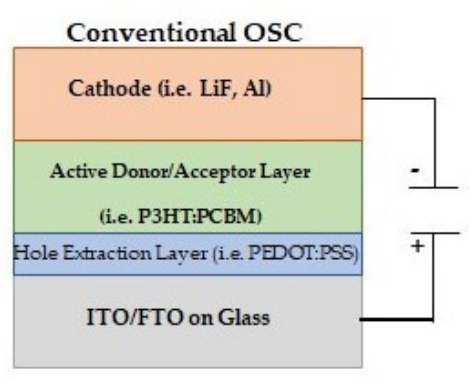

B

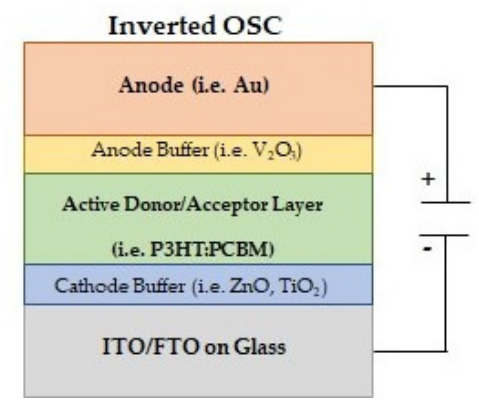

Scheme 3. Schematic representations of (A) conventional and (B) inverted organic solar cells (OSCs) with some of the more common materials listed for the various components.

A blend of poly(3-hexylthiophene) (P3HT) and the fullerene derivative (6,6)-phenylC61 butyric acid methyl ester (PCBM) is the most commonly employed material in polymer solar cells [80]; these devices can be considered naturally nanostructured because of the phase separation between the polymer and the fullerene derivative. Unfortunately, the thickness of these devices is limited by the poor carrier mobility of the organic semiconductors, which leads to undesirable charge recombination. Thus, they suffer from insufficient light harvesting capabilities and low power conversion efficiencies. To circumvent these issues, semiconductor quantum dots and various carbon-based nano-materials, like nanotubes, graphenes, and fullerenes, were incorporated into the devices as electron acceptor materials. However, all these materials have seen limited implementation because of problems of toxicity of the semiconductor quantum dots and of inhomogeneous interfacial contact, due to the propensity of aggregation of the carbon-based nano-materials [81,82]. In recent years, another class of OSCs, known as inverted organic solar cells (iOSCs), have recently become an object of great attention because they exhibit superior device stability and manufacturing capability. Compared with the conventional BHJ OPVs, in the 
architecture of iOSCs, the bias across the device is reversed; thus, the charges are extracted in the opposite direction (Scheme 3B). Because of the particular nature of the device, it is necessary to put buffer layers, sometimes known as electron transport layers (ETL), between the cathode (e.g., ITO-coated glass) and the polymer film to reduce the cathode work function and enhance the sustained separation and subsequent extraction of charge carriers. Metal oxides, like $\mathrm{ZnO}$ or $\mathrm{TiO}_{2}$, are the most commonly employed ETL materials. In recent works, $\mathrm{Cs}_{2} \mathrm{CO}_{3}$ is also employed because of its good electron injection and ease of fabrication. However, it was found that it can cause inadequate device stability because the $\mathrm{Cs}^{+}$ ions diffuse through the polymer layer with irreparable device-damages, and it has poor hole blocking ability, which leads to increased charge recombination $[83,84]$. From these considerations, CDs, in BJH organic solar cells, can act as electron acceptors when the active layer of P3HT is employed [43,85]. Furthermore, in solar cells, where the interface recombination at the heterojunction is suppressed, CDs can be employed in the electron blocking layer [86,87]. In inverted solar cells, CDs are used to alter the ETL through the reduction of the energy barrier for the electron transfer and the improvement of photoinduced excitation/dissociation and charge transfer [88]. In the following, some examples are reported.

\subsubsection{Electron Donors/Acceptors}

CDs can be employed as electron acceptors in two ways: (i) the CDs are co-mingled in the active layer of the device; and (ii) CDs replace the fullerene derivative. The electronaccepting capability of GQDs was studied by Kim et al. [89]. The architecture of the device is ITO/PEDOT:PSS/PTB7:PC71BM:GQDs/Al, and the employed GQDs were: (i) one acidoxidized and (ii) two subsequently reduced for $5 \mathrm{~h}$ and $10 \mathrm{~h}$, respectively. As Figure 7A-D show, the oxidized GQDs exhibit higher absorption, while the 10-h-reduced GQDs showed increased conductivity; when $0.5 \%$ wt of 5-h-reduced GQDs was employed for the device realization, the suitable balancing between light absorption and electrical conductivity was obtained, together with an enhancement of the device performance, when compared with the devices without the inclusion of GQDs. GQDs with an estimated LUMO energy level value in the range of $4.2 \mathrm{eV}-4.4 \mathrm{eV}$, and supposed to form an electron transport cascade, were employed by Qu et al. [41] for the realization of the BHJ solar cells with the structure ITO/PEDOT:PSS/P3HT:GQDs/Al. They found that the PV performance of the device was notably improved, upon the incorporation of the GQDs, showing an open-circuit voltage of $0.67 \mathrm{~V}$ and a power conversion efficiency (PCE) of $1.28 \%$.

Aniline-functionalized GQDs (ANI-GQDs) dispersed in conjugated polymers were employed by Gupta et al. [90] to enhance the performance in BHJ solar cells when compared to the blends of graphene sheet (GS) and conjugated polymers. They showed that, under $100 \mathrm{~mW}$ AM 1.5 G illumination, the device with $1 \mathrm{wt} \%$ ANI-GQDs in P3HT exhibited a PCE of $1.14 \%$, an open-circuit voltage $\left(\mathrm{V}_{\mathrm{oc}}\right)$ of $0.61 \mathrm{~V}$, a short-circuit current density $\left(\mathrm{J}_{\mathrm{Sc}}\right)$ of $3.51 \mathrm{~mA}$, and a fill factor (FF) of 0.53 (Figure 8). 

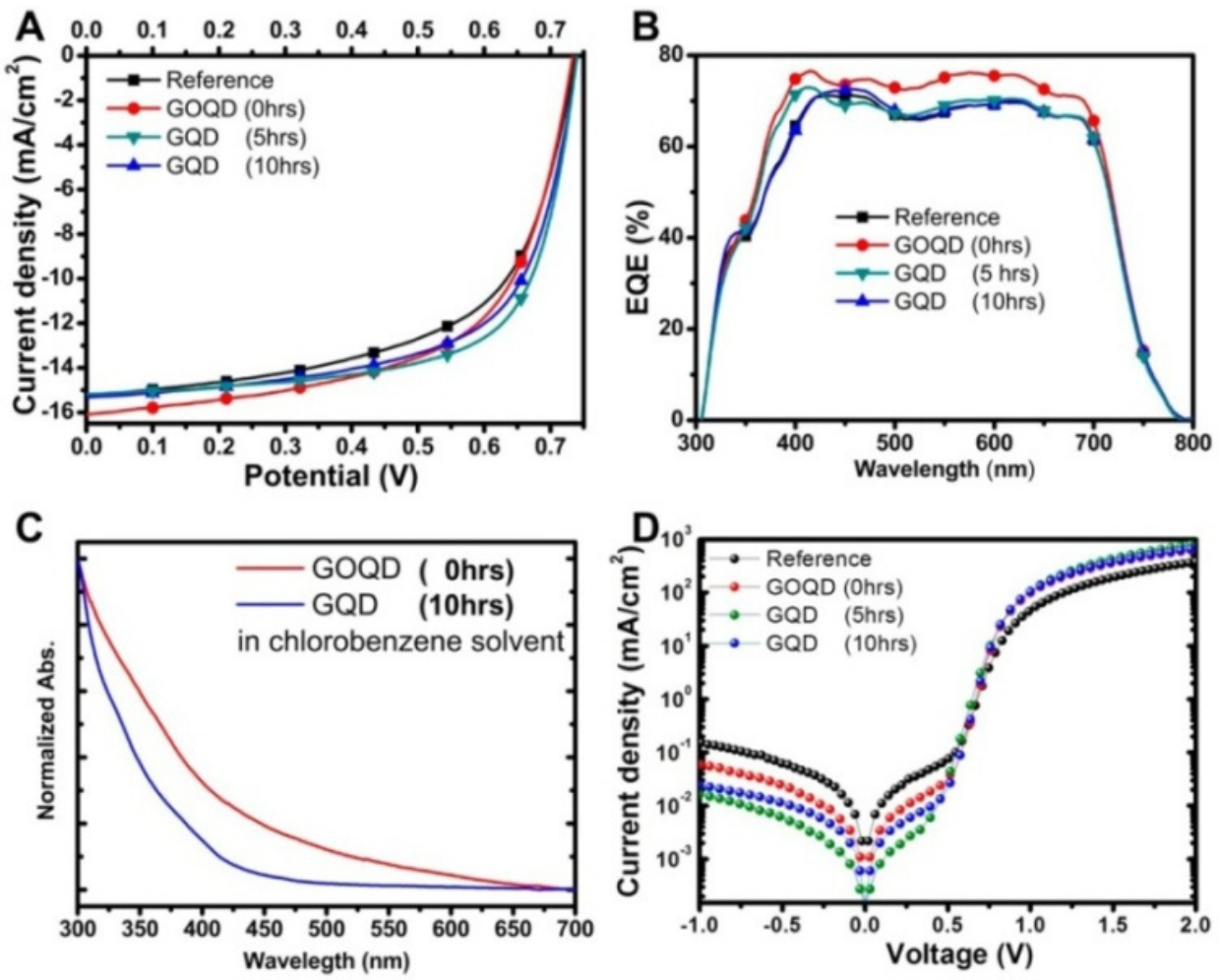

Figure 7. (A) Current versus potential J-V curves of the reference and three different GQD-BHJ devices. (B) Incident photon to charge carrier efficiency (IPCE) of the reference and GQD-BHJ devices. (C) UV-visible adsorption spectra of GOQD and GQD 10 in chlorobenzene. (D) Dark J-V curves of the BHJ devices with no GQDs (black), GOQD (red), GQD 5 (green), and GQD 10 (blue). Reprinted with the permission of Reference [89]. Copyright 2013 American Chemical Society.

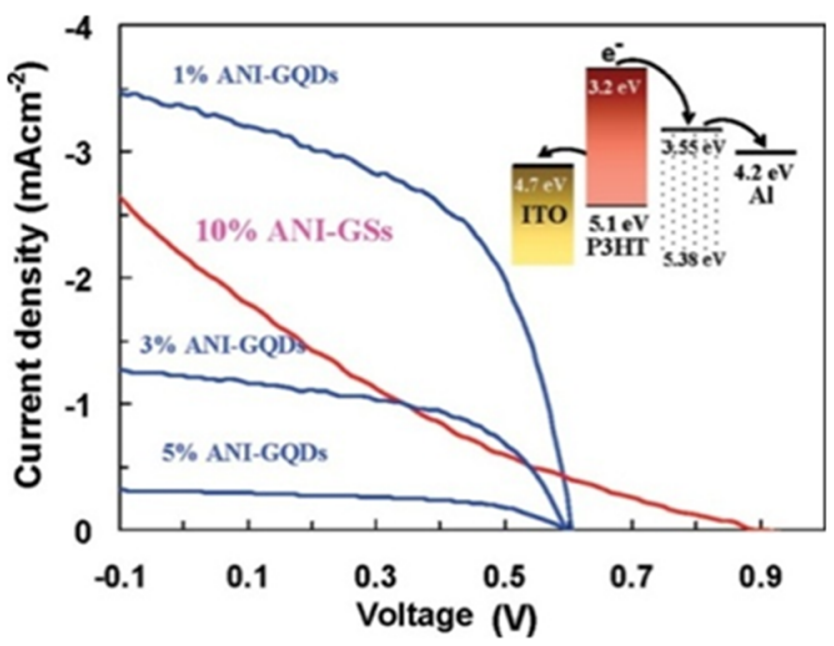

Figure 8. J-V characteristics of the photovoltaic (PV) devices based on Aniline-functionalized GQDs (ANI-GQDs) with different GQDs content and ANI-graphene sheet (GS) (under optimized condition) annealed at $160^{\circ} \mathrm{C}$ for $10 \mathrm{~min}$, under AM $1.5 \mathrm{G} 100 \mathrm{~mW}$ illumination. Reprinted with the permission of Reference [90]. Copyright 2011 American Chemical Society.

CDs can also be coupled with the PCBM fullerene derivatives with the function of electron donors or co-electron acceptors. In general, literature reports studies where CDs acts as acceptors, and there are few works dealing with the role of CDs as electron donors outside the context of injecting electrons into metal oxides [91-94]. Privitera et al. [91] pre- 
pared organosoluble $\mathrm{N}$-doped CDs functionalized with thiopene that showed to be efficient electron donors to PCBM in both solution and solid blends. They also demonstrated that the observed longer-lived charge pair states, which lead to increased charge recombination and reduce the amount of the free charge carriers that are photoinduced, are dependent on the employed thiophene moiety.

\subsubsection{Hole Extraction Layer}

Hole extraction layers (HELs) are commonly employed to facilitate charge separation and prevent interfacial recombination within $\mathrm{BHJ}$ in order to obtain devices with high performance. PEDOT:PSS is the most widely used HEL. However, owing to its strong acidity and hygroscopicity, it causes undesirable instability of the devices [95,96]. HELs based on inorganic semiconducting materials are known to enhance the stability of the devices, but they suffer from the limit of increasing their manufacturing costs [97]. In this scenario, CDs could be a suitable alternative to both these issues. For example, Lim et al. [98] obtained core-shell GQD@PEDOT nanostructures (CSNS) through the incorporation of GQDs (prepared from the oxidation of carbon nanofibers) into PEDOT:PSS. They showed that the employment of isopropyl alcohol (IPA) during the CSNS preparation contrasted the interaction between the PDOT and the PSS ions and caused the formation of negatively-charged GQDs surrounded by PEDOT cations (Figure 9).

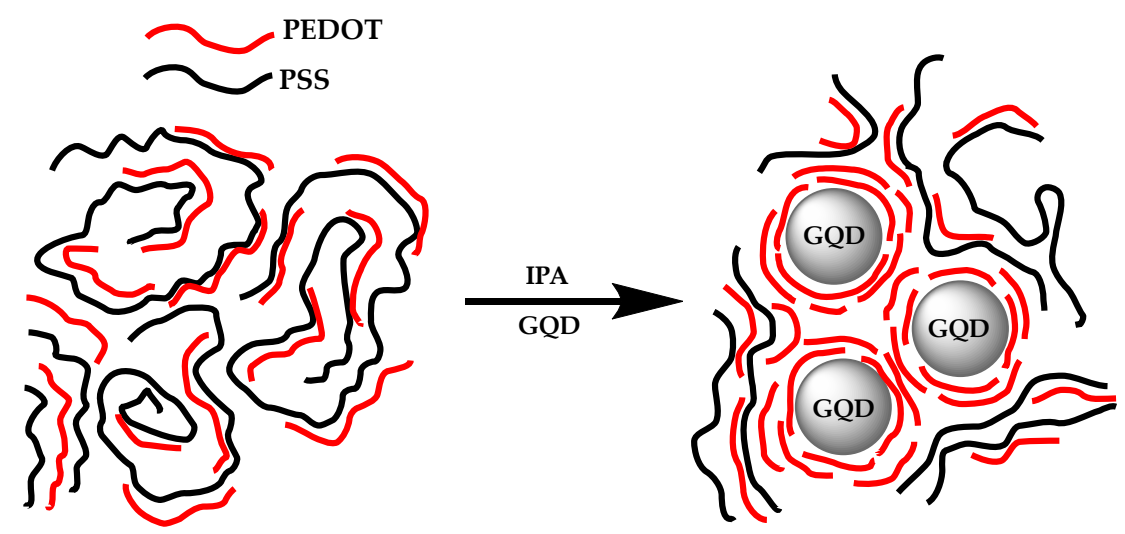

Figure 9. Schematic representation of the core-shell nanostructures (CSNS) formation of the GQD@PEDOT. Reprinted with the permission of Reference [97]. Copyright 2015 American Chemical Society.

The film obtained by the gelation of such CSNS presents improved morphologies where the GQDs are surrounded by relatively homogeneous and interconnected PEDOTrich domains, which lead to better charge hopping pathways and, therefore, enhance the film conductivity. The PV performances of the devices realized employed the CSNS as HEL are reported in Table 1. It is interesting to note that the addition of $20 \%$ vol of GQDs ( ${ }_{0} \mathrm{G}_{0.2}$ in Table 1) caused an increase of $20 \%$ in the PCE compared to a PEDOT:PSS layer without GQDs. However, when the GQD quantity was increased to $50 \mathrm{vol} \%\left(\mathrm{ogg}_{0.5}\right.$ in Table 1), a negative effect on the PV performance (JSC and PCE) was observed compared to the $20 \mathrm{vol} \%$ device (ogG 0.2 in Table 1 ). The improved $\mathrm{J}_{S C}$ and PCE values observed in both the GQDs-incorporated devices are plagued by lower FFs arising from lowered shunt resistances that result in current leakages between the electrodes. 
Table 1. Photovoltaic (PV) performance of organic PVs (OPVs) with various hole extraction layers (HELs) ${ }^{a}$.

\begin{tabular}{|c|c|c|c|c|}
\hline HEL & $\mathrm{J}_{\mathrm{sc}}\left(\mathrm{mA} \mathrm{cm}{ }^{-2}\right)$ & $\mathrm{V}_{\mathrm{oc}}(\mathrm{V})$ & FF & PCE (\%) \\
\hline pristine & 11.97 & 0.58 & 0.54 & 3.77 \\
\hline $\operatorname{ogG}_{0.2}$ & 16.08 & 0.59 & 0.50 & 4.74 \\
\hline $\operatorname{og} G_{0.5}$ & 14.59 & 0.58 & 0.48 & 4.08 \\
\hline
\end{tabular}

${ }^{a}$ Device structure in all cases is ITO/HEL/P $£ H T: \mathrm{PC}_{61} \mathrm{BN} / \mathrm{LiF} / \mathrm{Al}$. Reproduced with the permission of Reference [97]. Copyright 2015 American Chemical Society.

In another work [91], small size CDs (ca $4 \mathrm{~nm}$ ) with work function of $5.26 \mathrm{eV}$ and a good film forming capability were employed as HEL in PSCS. The performance of the fabricated device showed to be better than that of a similar device built employing graphene oxide and PEDOT:PSS, reaching a PCE as high as 7.91\%. Samal et al. [98] synthesized graphene quantum rings (GQRs) with a work function of $-4.6 \mathrm{eV}$ from pitch carbon by thermal hydrolysis process. The GQRs were incorporated into PEDOT:PSS, and the obtained composite was employed as HEL in solar cells, having a silver electrode grid on PEDOT:PSS:GQRs as cathode and a rear metal (Al) electrode as anode, respectively (see Figure 10a). The device performances, shown in Figure 10, were measured under simulated $100 \mathrm{~mW} / \mathrm{cm}^{2}$ AM $1.5 \mathrm{G}$ illumination. The PCE passed from $5.1 \%$ in the reference devices to $7.4 \%$ in the device with HEL layer incorporating the GQRs.

(a)
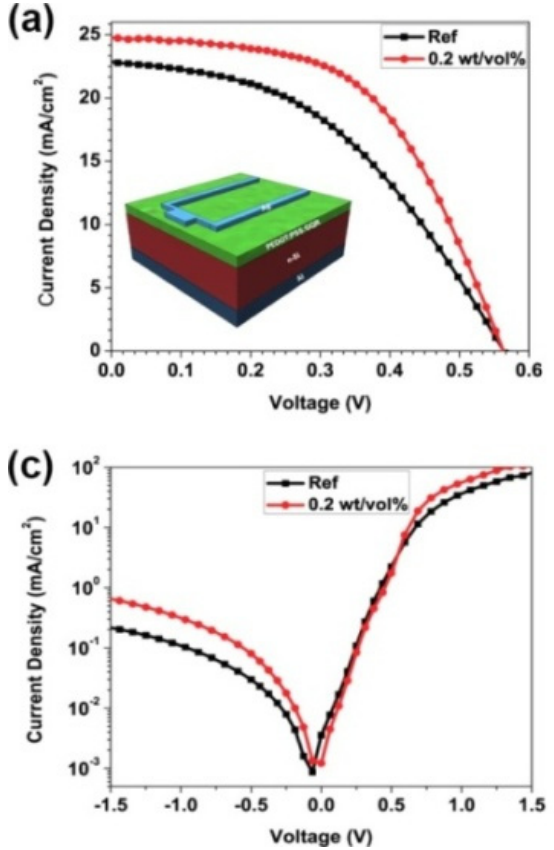

(b)
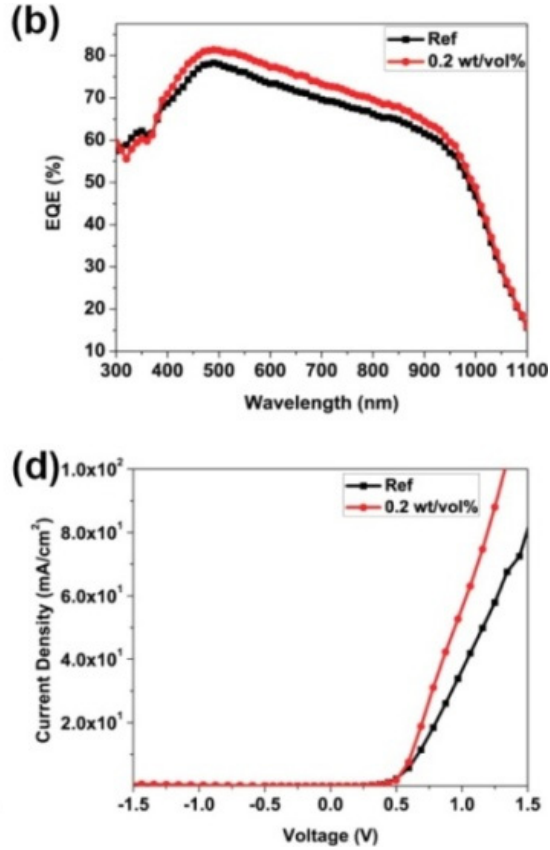

Figure 10. Characteristics of the fabricated device structure Ag/PEDOT:PSS/Si/Al with and without GQRs. (a) Current density versus voltage characteristics of reference and optimized device; inset image shows device structure. (b) External quantum efficiency (EQE). (c) Dark current for leakage. (d) Dark current. Reprinted with the permission of Reference [98]. Copyright 2015 American Chemical Society.

\subsubsection{Electron Transport Layer (ETL)}

Among the ETLs employed in iOSCs $\mathrm{ZnO}$ is one of the most extensively used. However, $\mathrm{ZnO}$ is characterized by numerous surface defects and energy bands misaligned with the photoactive layer which make light-soaking processes necessary to achieve high performances for the cells based on this oxide. In recent reported works, CDs were employed as surface modifiers of $\mathrm{ZnO}$ to overcome the light-soaking effect. Ma et al. [99] prepared Nitrogen and Sulfur co-doped CDs (N,S-CDS) as efficient surface modifiers for 
$\mathrm{ZnO}$. They prepared the iOSCs with the configuration of ITO/ZnO (or ZnO:N-CQDs or $\mathrm{ZnO}: \mathrm{N}, \mathrm{S}-\mathrm{CDs}$ )/PTB7-Th:PC71BM/ $\mathrm{MoO}_{3} / \mathrm{Al}$ (Figure 11a).

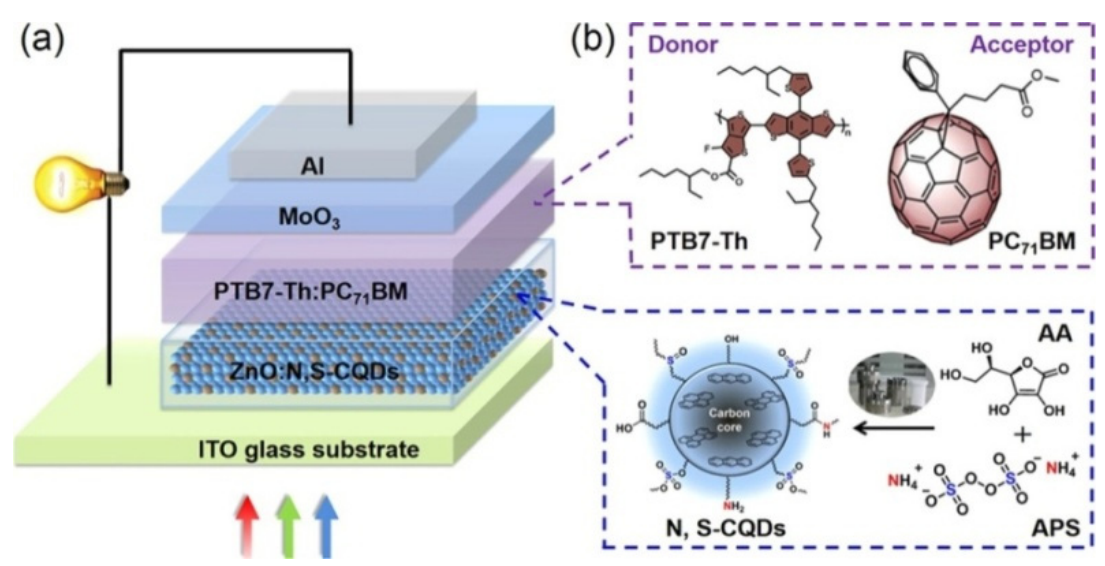

Figure 11. (a) Device configuration of inverted OSCs and (b) structural formula of active layer materials and sketch map of the synthesis of Nitrogen and Sulfur co-doped carbon quantum dots (N,SCQDs). Reprinted with the permission of Reference [99]. Copyright 2019 American Chemical Society.

As Figure 12a shows, the J-V characteristic of the devices containing ZnO:N,S-CDs is light soaking free and shows a superior performance of $9.31 \%$, thus indicating that the insertion of N,S-CDs can reduce the energy barrier and increase the charge from the active layer to the ETL through the elimination of the light-soaking issue and the maximization of the stabilized device efficiency. Additionally, the slightly enhanced JSC (Figure 12b) could be ascribed to an improvement in interfacial connection between $\mathrm{ZnO}$ and photoactive layer, as well as the light absorption in the photoactive layer, by introducing the N,S-CQDs. Guo et al. [100] employed polymer-functionalized CDs as ETL in the iOSCs. The CDs were prepared through microwave assisted synthesis starting from citric acid and urea. The CDs rich in hydroxyls and carboxyls were self-assembled on the amino-rich polyethyleneimine (PEI) to give the CDs@PEI composite. The local states inside CDs@PEI can work as a light-controlling switch that inhibits the leakage current and facilitates electron extraction through light-induced electron filling and release. The structure of the realized device is indium tin oxide (ITO)/ETL/PTB7:PC71BM/ $\mathrm{MoO}_{3} / \mathrm{Ag}$, with PEI, polyfluorene (PFN), $\mathrm{ZnO}, \mathrm{TiO}_{2}$, and CDs@PEI employed as ETL, respectively, and $\mathrm{MoO}_{3}$ as hole-transport layer. The CDs@PElbased device showed the best efficiency of $9.53 \%$ with a $\mathrm{V}_{\mathrm{oc}}$ of $0.73 \mathrm{~V}$, a J $\mathrm{J}_{\mathrm{sc}}$ of $18.37 \mathrm{~mA} \mathrm{~cm}^{-2}$, and an FF of $71.14 \%$ (Table 2).
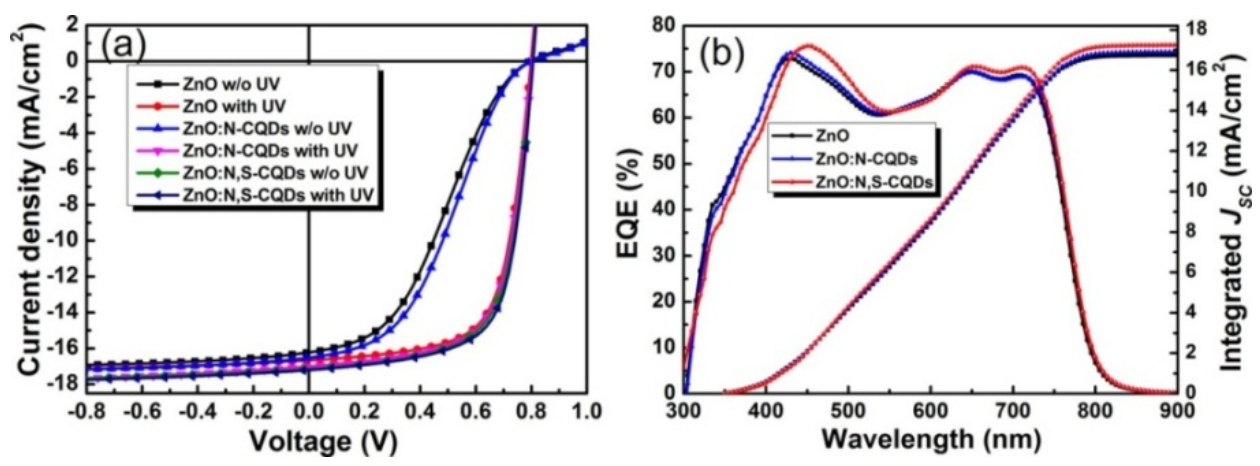

Figure 12. (a) J-V curves without and with UV treatment and (b) EQE spectra with UV treatment of ZnO-, ZnO:N-CQD-, and ZnO:N,S-CQDs-based PTB7-Th:PC71BM solar cells. Reprinted with the permission of Reference [99]. Copyright 2019 American Chemical Society. 
Table 2. Photovoltaic (PV) parameters of the devices with different electron transport layers (ETLs).

\begin{tabular}{ccccc}
\hline Device & $\mathbf{V}_{\mathbf{~ o c}}(\mathbf{V})$ & $\mathbf{J}_{\mathbf{s c}}\left(\mathbf{m A ~ c m} \mathbf{~ c m}^{-2}\right)$ & FF /\%) & PCE (\%) \\
\hline ITO/PEI & 0.73 & 16.46 & 60.56 & 7.25 \\
ITO/PFN & 0.74 & 18.17 & 61.93 & 8.29 \\
ITO/ZnO & 0.74 & 16.20 & 67.15 & 8.04 \\
ITO/TiO 2 & 0.80 & 16.26 & 60.52 & 7.90 \\
ITO/C-dots@PEI & 0.73 & 18.37 & 71.14 & 9.53 \\
\hline
\end{tabular}

Reproduced with the permission of Reference [100]. Copyright 2018 American Chemical Society.

Furthermore, the CDs@PEI-based devices exhibit a suppressed dark current and an improved electron extraction under illumination. In another work, Lim et al. [101] employed CDs, obtained from citric acid and ethanediamine, to prepare a composite with polyethylenimine ethoxylate (PEIE). The obtained composite material was implanted as ETL in iOSC. The authors show that the presence of the CDs below the active layer improve the transport properties and the power conversion passes from $7.90 \%$ in the control device to $8.35 \%$ in the iOSCs with the CDs.

\subsection{Dye Sensitized Solar Cells (DSSCs)}

DSSCs devices typically consist of a sensitized photoelectrode $\left(\mathrm{TiO}_{2}\right.$ or $\mathrm{ZnO} /$ sensitizer $)$, electrolyte $\left(\mathrm{I}_{3}{ }^{-} / \mathrm{I}^{-}\right)$, and counter electrode (CE). In general, the sensitizers employed in DSSCs offer great performances but require long-time synthesis routes because they are based on a Ru-metal center, which is scarce, expensive [102], and needs to be replaced by more sustainable and environmentally friendly alternatives. On the other side, the $\mathrm{Pt}$, deposited as a thin film onto a transparent conductive oxide-coated glass substrate is one of the most common CE employed in DSSCs. In fact, Pt proved to have a high catalytic activity toward reducing $\mathrm{I}_{3}{ }^{-}$[103], producing some of the best PV performances. However, in DSSCs production, $\mathrm{Pt}$ is one of the most expensive components. Recently, $\mathrm{Pt}$ films were replaced by conducting polymer films, like polypyrrole (PPy), because of their ease of production and low costs [104-106]. However, the relatively high charge transfer resistance observed in conducting polymers limits their practical applications $[107,108]$ in DSSCs. Within this scenario, CDs are regarded to be both alternatives to photoanode sensitizers and components of $\mathrm{CE}$. In fact, in the former case, the surface of CDs presents carboxylate functionalities which enable anchoring on $\mathrm{TiO}_{2}$ or $\mathrm{ZnO}$ surface; moreover, as above reported, the band matches of $\mathrm{TiO}_{2}$ and $\mathrm{CDs}$ are suited for the injection of photo-generated electrons of CDs into the conduction band of the neighboring $\mathrm{TiO}_{2}$, which is in intimate contact (see Scheme 1). In the latter case, CDs, owing to their interesting electronic properties (i.e., charge transfer, electron acceptor, electron donator), could be employed as doping conductive materials to overcome the poor conductivity of the conductive polymers employed to replace $\mathrm{Pt}$ in CE. In the following section, some examples of the employment of CDs in DSSCs, both as sensitizers and as CE components, will be reported.

\subsubsection{Sensitizers}

The CDs prepared from Gelidium amansii powder (a type of red algae) were employed in combination with N719 dye as light-harvester in a co-sensitized solar cell [109]. The cell was prepared with FTO glass support for the $\mathrm{CDs} / \mathrm{N} 719 / \mathrm{TiO}_{2}$, for the photoanode, FTO glass supported $\mathrm{Pt}$ for the counter electrode, and $\mathrm{I}^{-} / \mathrm{I}_{3}{ }^{-}$redox electrolyte (Figure 13a). 

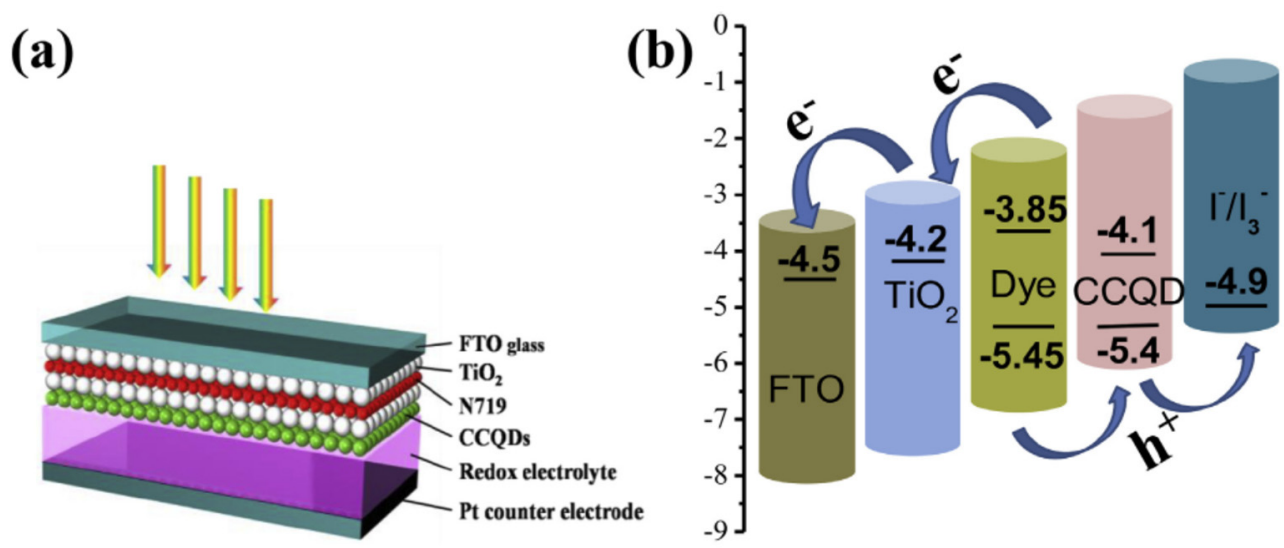

Figure 13. (a) Schematic diagram of a mesoscopic solar cell tailored with CCQDs and N719 dye. (b) The energy level distribution and charge transfer within the photoanode. Reprinted with the permission of Reference [109]. Copyright 2018 Elsevier Ltd.

The autors show that the HOMO level of CDs is aligned with the one of the N719 dye, and the value of the redox potential of $\mathrm{I}^{-} / \mathrm{I}_{3}{ }^{-}$system shows that there is a bridge for extraction of holes from N719 to the electrolyte which leads to an improvement of charge separation (Figure 13b). In another study, $\mathrm{ZnO}$ nanoparticles functionalized with CDs were used in a DSSC [110]. The device performances were determined under the source of stimulated light at $156 \mathrm{w} / \mathrm{m}^{2}$. The authors show that the addition of $10 \% \mathrm{wt}$ of CDs into the $\mathrm{ZnO}$ nanoparticles determined an increase of conversion efficiency of the device which is 7 times higher if compared with the device with CDs-free $\mathrm{ZnO}$ nanoparticles. Furthermore, the charge transfer resistance for the DSSCs with the CDs-hybridized ZnO nanoparticles was lower in comparison with the DSSCs with CDs-free ZnO nanoparticles. In Figure 14A, the scheme of the photoanode is reported. The excitation of the dye by sunlight causes the separation of the electron/hole pair in the $\mathrm{ZnO}$ nanoparticles. The CDs prevent the recombination of the electron/hole pair in $\mathrm{ZnO}$ nanoparticles and favor the electron transfer from the CD-donor to the conductive band level of the n-type $\mathrm{ZnO}$ semiconductor or the donation of the energy in excited CD, enhancing the PV effect. The separated electrons are then transferred to the ITO. In Figure 14B, it is possible to note that the Voc is influenced by the sensitizer species, size of $\mathrm{ZnO}$ nanoparticles, and CDs content, while the FF seems to not be affected by these factors.

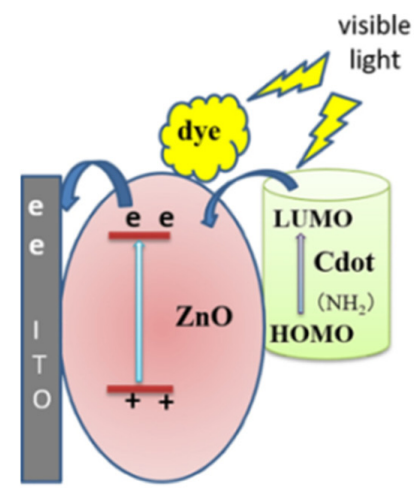

(A)
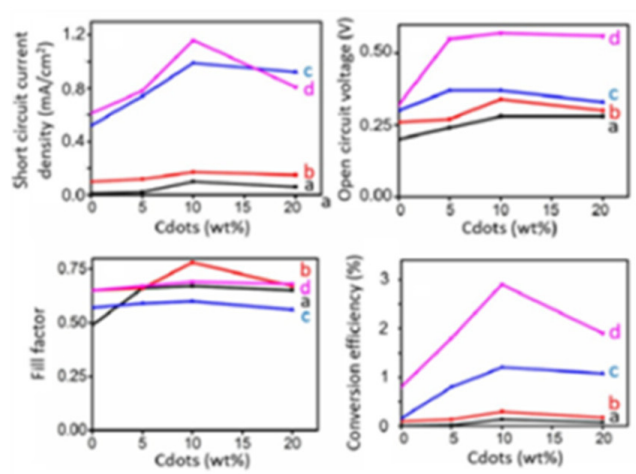

(B)

Figure 14. (A) Schematic illustration of anode in dye sensitized solar cell (DSSC). (B) Plots of electrochemical parameters from ZnO@Cdots/dye DSSCs as a function of Cdots content for (a) ZnO(100)@Cdots(1)/RhB, (b) ZnO(20)@Cdots(1)/RhB, (c) $\mathrm{ZnO}(100) @ \operatorname{Cdots}(1) / \mathrm{N} 719$, and (d) ZnO(20)@Cdots(1)/N719. Reprinted with the permission of Reference [110]. Copyright 2019 Elsevier Ltd. 
The working performaces of a solar cell in different weather conditions, together with the preventing of the photo-degradation of the sensitizer due to the UV light of the sun, are two great challenges in DSSCs designing. In fact, in the former case, the low light weather causes a lack in the light absorber excitation and then a lack in the electricity production of the PV device, while, in the latter case, the photo-degradation of the sensitizer (in particular, the Ru-free dyes) limits the stability of the DSSCs during long term periods. Literature reports that CDs obtained from biomass, when employed in solar cells, determined electricity production both in daylight and in the dark [111]. Plenty of other research works reporting the synthesis of CDs starting from biomass as carbon source are present in literature [112-114]. A proposed DSSCs configuration employs long persistence green-emitting phosphors. These ones combined with $\mathrm{TiO}_{2}$ favors storage of part of sunlight in the photoanode which is able to illuminate and excite by green light in the dark. The devices present a conversion efficiency of $7.97 \%$ with persistent production of electricity for several hours. In the device configuration, the CDs absorb part of the sunlight, while the unabsorbed one will be stored by the green-emitting phosphors in which emission will irradiate the CDs in the dark [111]. Another proposed DSSC configuration combines the green-emitting phosphors with the co-sensitized N-doped CDs and N719 dye [115]. In this case, the CDs both increase the spectral absorption and quick charge extraction in the cell. Under sun illumination, the power conversion efficiency passes from $8.09 \%$ for the CDs-free device to $9.29 \%$ for the device including the $\mathrm{CDs}$. The $\mathrm{TiO}_{2} /$ long persistence phosphor photo anode enables achieving a persistent power generation. Figure 15 reports the structure of the DSSC together with the charge transfer processes among the energy levels at the interface of the photoanode/electrolyte and the J-V characteristics.
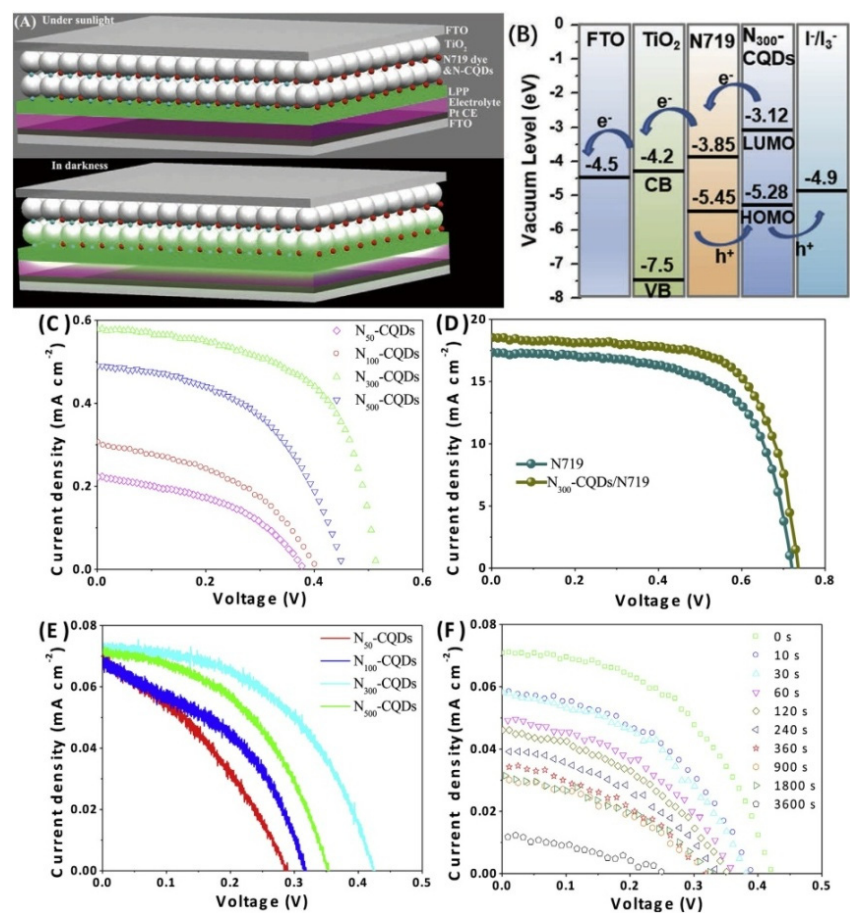

Figure 15. (A) Schematic diagram of the N300-CQDs and N719 co-sensitized DSSCs with a m$\mathrm{TiO}_{2}$ /LPP photoanode. (B) Energy level distribution and charge transfer processes at photoanode/electrolyte interface. Representative photo J-V characteristics of the solar cells sensitized by (C) various N-CQDs and (D) N719 dye and N300-CQDs/N719 under simulation solar irradiation (100 $\mathrm{mWcm}^{-2}$, AM 1.5), and (E) in completely dark conditions. (F) Dark J-V curves for N300-CQDs sensitized solar cells using $\mathrm{m}-\mathrm{TiO}_{2} / \mathrm{LPP}$ photoanode at various decay times. Reprinted with the permission of Reference [115]. Copyright 2018 Elsevier Ltd. 
On the other side, to mitigate the problem of photo-degradation, energy-down-shift (EDS) materials are employed in the realization of solar cells. These materials are able to absorb UV light (or generally the high energy photons) and simultaneously emit low enery ones. Thus, the sensitizer can absorb the down-converted visible light, preventing photodegradation. CDs can act as EDS, so they can be employed as a layer in the outer surface of the DSSC responsible for increasing the performance of the solar cell in the wavelength range of 300-400 nm. Literature [116] reported the synthesis of properly designed N-doped CDs which emit in the green wavelength region $(500-550 \mathrm{~nm})$, which were employed as EDS in DSSCs. The CDs determined the conversion of the sunlight into green light causing an improvement of $10 \%$ of the power conversion of the DSSCs (Table 3). Furthermore, the stability of the solar cell under UV irradiation of the sunlight is also improved.

Table 3. Summary of J-V measurements of DSSC at different CQD coating cycles.

\begin{tabular}{ccccc}
\hline Device & $\mathbf{V}_{\mathbf{o c}}(\mathbf{V})$ & $\mathbf{J}_{\mathbf{s c}}\left(\mathbf{m A ~ \mathbf { ~ m } ^ { - 2 } )}\right.$ & FF (\%) & PCE (\%) \\
\hline CQD 0 & $0.73 \pm 0.012$ & $13.5 \pm 0.018$ & $74.52 \pm 0.25$ & $7.3 \pm 0.051$ \\
CQD 1 & $0.73 \pm 0.011$ & $14.0 \pm 0.013$ & $74.46 \pm 0.24$ & $7.6 \pm 0.054$ \\
CQD 2 & $0.73 \pm 0.013$ & $14.5 \pm 0.019$ & $74.42 \pm 0.26$ & $7.8 \pm 0.052$ \\
CQD 3 & $0.73 \pm 0.010$ & $15.0 \pm 0.018$ & $75.29 \pm 0.24$ & $8.2 \pm 0.053$ \\
CQD 4 & $0.73 \pm 0.012$ & $14.7 \pm 0.017$ & $74.90 \pm 0.24$ & $8.0 \pm 0.055$ \\
\hline
\end{tabular}

Reproduced with the permission of Reference [116]. Copyright 2018 Copyright Elsevier Ltd.

\subsubsection{Counter Electrode}

Another employment of CDs in DSSCs is in combination with conductin polymers as alternatives to Pt in CE. For example, films based on polypyrrole doped with GQDs employed as CE determined an increase of ca. 20\% of the DSSCs PCE (5.27\%) when compared with the PCE (4.46\%) of the DSSCs with polypyrrole without CDs as CE. The obtained PCE value is comparable with the one of a Pt CE (6.02\%) [117]. Polyaniline (PANI) doped with CDs revealed to be an interesting material for CE in DSSCs [118,119]. In fact, it was observed that CDs act as an efficient nucleating agent for aniline polymerization, which generate prous PANI/CDs structures characterized by high surface area $\left(43.6 \mathrm{~m}^{2} \mathrm{~g}^{-1}\right)$, an electrical conductivity increased of ca. $774 \mathrm{~S} \mathrm{~cm}^{-1}$, and an enhanced degree of paracoupling in the PANI microstructure. Thus, the DSSCs realized with PANI/CDs film as CE exhibited a PCE of 7.45\% [118]. An all-carbon CE, which consists of a GQD-decorated carbon aerogel (GQDs/CA), was developed by Lu et al. [120] to be employed as CE in DSSCs. It was observed that the electrocatalitic efficiency of this carbon-based electrode is similar to the one of Pt electrode, while long term stability is even better. CDs can be used in bifacial dye-sensitized solar cells (DSSCs), which are capable of harvesting the sunlight from both sides of the cell. In these types of solar cells, when the solar cell panels are installed in the power generation station, the front side of the row of the solar cells in the back can reflect the sunlight on the backside of the solar cell panels that are installed in the front (Scheme 4). As the transparency of Pt is very low, the traditional Pt CE of DSSCs can be used in their front side for light absorption. A bi-tandem solar cell with transparent CoSe as CE was designed through the incorporation of CDs. The front and back conversion efficiencies passed from $7.87 \%$ and $5.03 \%$, respectively, for the CD-free device to $8.54 \%$ and $6.55 \%$, respectively, for the device with CDs. The photo-excited electrons from bitandem CDs and electron accumulation on the counter electrode have resulted in an enhancement in conversion efficiency [121]. 


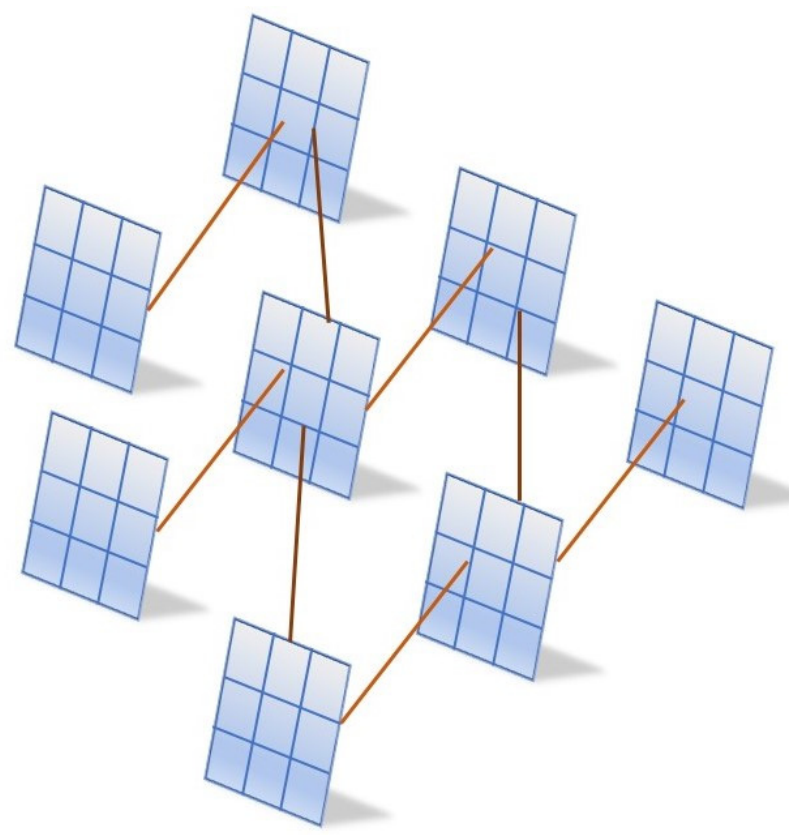

Scheme 4. Schematic representation of bifacial solar panels station.

\section{Final Remarks and Perspectives}

This short review aimed, on one side, to show how the optical properties of CDs, i.e., fluorescence, band gap, and energy levels, can be tailored by suitable synthetic and post-synthetic strategies, leading to controlling their size, crystallinity, surface functional groups, and doping-heteroatoms. On the other side, these interesting research results reveal that CDs can be successfully employed as components, both in OSCs and in DSSCs architectures. It has been shown that CDs can cover multiple roles in these OPVs devices, going from sensitizers to charge carrier layers and counter electrodes. All the reported cases exhibit that the employment of CDs in these OPVs architectures, independently of the role covered, improves their performances. By the way, a brief comparison with the recent advances in OSCs and DSSCs could be done in order to check the real advantages reprentented by the employment of CDs. In the case of OSCs, recently developed smallmolecules, known as non-fullerene acceptors (NFAs), have proven to be a better fullerene alternative than CDs in BHJ OSCs, reaching device PCEs of $17 \%$ for both a single junction and tandem cells [122,123] (ca. one order of magnitude higher than the ones reported for the cells with CDs). Another recent work [124] reports how the thickness of a BHJ based on fullerene and intermediate-size molecules of new generation can influence the performances of both conventional and inverted OSCs. So, it could be interesting to develop these studies by employing CDs in place to investigate the variations of the OSCs performances. On the other side, regarding DSSCs, a recent work reports a PCE of $14.2 \%$ reached for traditional devices employing $\mathrm{I}^{-} / \mathrm{I}_{3}{ }^{-}$redox couple and cobalt-porphyrin as sensitizer. This value is higher than the ones reported for the CDs-based DSSCs [125]. Thus, from these considerations, it results that the employment of CDs in BHJ OSCs and DSSCs improves their performaces, but, at present, without reaching record values. In any case, despite these remarks, CDs could be considered a challenging alternative to the inorganic semiconductor-based quantum dots and sensitizers, based on heavy metal complexes, usually employed for the realization of OSCs and DSSCs, respectively, because they exhibit the advantage of being cheap, sustainable (they could be also obtained from renewable precursors), and nontoxic; in particular, their water solubility prevents the employment of hazardous solvents usually required for processing small and intermedite-size organic molecules. In fact, it has to be taken into account that the research on CDs is still at its beginnings, and some research aspects still have to be studied and developed. For example, the reported synthesis methods of CDs, in general, lack reproducible and scalable strategies 
able to realize CDs with defined properties, like size, shape, crystallinity, defects location, etc. The realization of CDs with a defined purity level is an important challenge in CDs research studies. This last aspect may also influence the application of CDs in solar energy conversion devices, as the performaces of the devices may be influenced by the eventual presence of impurities, which make it difficult to define the effective contribution of the CDs. Thus, it could be interesting to develop suitable in-situ techniques able to characterize the formation mechanisms of CDs during the different synthetic strategies in order to better understand the correlation between the structure and the properties of these nanomaterials. Another challenging research aspect on CDs that could be examined is their employment in NFAs-based OSCs in order to study the effect on their performances.

Funding: This research was funded by the Italian government MUR.

Conflicts of Interest: The authors declare no conflict of interest.

\section{References}

1. Grätzel, M. Recent Advances in Sensitized Mesoscopic Solar Cells. Acc. Chem. Res. 2009, 42, 1788-1798. [CrossRef] [PubMed]

2. Guo, J.; Min, J. A Cost Analysis of Fully Solution-Processed ITO-Free Organic Solar Modules. Adv. Energy Mater. 2019, 9, 1802521. [CrossRef]

3. Glogic, E.; Weyand, S.; Tsang, M.P.; Young, S.B.; Schebek, L.; Sonnemann, G. Life cycle assessment of organic photovoltaic charger use in Europe: The role of product use intensity and irradiation. J. Clean. Prod. 2019, 233, 1088-1096. [CrossRef]

4. Gan, Q.; Bartoli, F.J.; Kafafi, Z.H. Plasmonic-Enhanced Organic Photovoltaics: Breaking the 10\% Efficiency Barrier. Adv. Mater. 2013, 25, 2385-2396. [CrossRef]

5. Xu, X.; Ray, R.; Gu, Y.; Ploehn, H.J.; Gearheart, L.; Raker, K.; Scrivens, W.A. Electrophoretic Analysis and Purification of Fluorescent Single-Walled Carbon Nanotube Fragments. J. Am. Chem. Soc. 2004, 126, 12736-12737. [CrossRef] [PubMed]

6. Zhou, Y.; Mintz, K.J.; Cheng, L.; Chen, J.; Ferreira, B.C.; Hettiarachchi, S.D.; Liyanage, P.Y.; Seven, E.S.; Miloserdov, N.; Pandey, R.R.; et al. Direct conjugation of distinct carbon dots as Lego-like building blocks for the assembly of versatile drug nanocarriers. J. Colloid Interface Sci. 2020, 576, 412-425. [CrossRef]

7. Zheng, Z.; Li, H.; Zhang, X.; Jiang, H.; Geng, X.; Li, S.; Tu, H.; Cheng, X.; Yang, P.; Wan, Y. High-absorption solar steam device comprising Au@Bi2MoO6-CDs: Extraordinary desalination and electricity generation. Nano Energy 2020, 68, 104298. [CrossRef]

8. Peng, Z.; Zhao, T.; Zhou, Y.; Li, S.; Li, J.; Leblanc, R.M. Bone Tissue Engineering via Carbon-Based Nanomaterials. Adv. Healthc. Mater. 2020, 9, e1901495. [CrossRef]

9. Dou, X.; Zheng, Y.; Uchiyama, K.; Lin, J.-M. Fluorescent carbon nanoparticles: Mimicking hydrogen peroxide properties in a chemiluminescence system. Chem. Commun. 2016, 52, 14137-14140. [CrossRef]

10. Zhao, H.X.; Liu, L.Q.; De Liu, Z.; Wang, Y.; Zhao, X.J.; Huang, C.Z. Highly selective detection of phosphate in very complicated matrixes with an off-on fluorescent probe of europium-adjusted carbon dots. Chem. Commun. 2011, 47, 2604-2606. [CrossRef] [PubMed]

11. Zheng, Y.; Zhang, D.; Shah, S.N.A.; Li, H.; Lin, J.-M. Ultra-Weak chemiluminescence enhanced by facilely synthesized nitrogenrich quantum dots through chemiluminescence resonance energy transfer and electron hole injection. Chem. Commun. 2017, 53, 5657-5660. [CrossRef]

12. Zhou, W.; Dong, S.; Lin, Y.; Lu, C. Insights into the role of nanostructure in the sensing properties of carbon nanodots for improved sensitivity to reactive oxygen species in living cells. Chem. Commun. 2017, 53, 2122-2125. [CrossRef]

13. Dong, S.; Yuan, Z.; Zhang, L.; Lin, Y.; Lu, C. Rapid Screening of Oxygen States in Carbon Quantum Dots by Chemiluminescence Probe. Anal. Chem. 2017, 89, 12520-12526. [CrossRef]

14. Chen, S.; Yu, Y.-L.; Wang, J.-H. Inner filter effect-based fluorescent sensing systems: A review. Anal. Chim. Acta 2018, 999, 13-26. [CrossRef]

15. Feng, J.; Wang, W.-J.; Hai, X.; Yu, Y.-L.; Wang, J.-H. Green preparation of nitrogen-doped carbon dots derived from silkworm chrysalis for cell imaging. J. Mater. Chem. B 2015, 4, 387-393. [CrossRef] [PubMed]

16. Li, Y.; Zhong, X.; Rider, A.E.; Furman, S.A.; Ostrikov, K. Fast, energy-efficient synthesis of luminescent carbon quantum dots. Green Chem. 2014, 16, 2566-2570. [CrossRef]

17. Zhang, Q.Q.; Yang, T.; Li, R.S.; Zou, H.Y.; Li, Y.F.; Guo, J.; Liu, X.D.; Huang, C.Z. A functional preservation strategy for the production of highly photoluminescent emerald carbon dots for lysosome targeting and lysosomal pH imaging. Nanoscale 2018, 10, 14705-14711. [CrossRef] [PubMed]

18. Gao, M.X.; Yang, L.; Zheng, Y.; Yang, X.X.; Zou, H.Y.; Han, J.; Liu, Z.X.; Li, Y.F.; Huang, C.Z. “Click” on Alkynylated Carbon Quantum Dots: An Efficient Surface Functionalization for Specific Biosensing and Bioimaging. Chem. A Eur. J. 2017, 23, 2171-2178. [CrossRef] [PubMed]

19. Molaei, M.J. The optical properties and solar energy conversion applications of carbon quantum dots: A review. Sol. Energy 2020, 196, 549-566. [CrossRef]

20. Bacon, M.; Bradley, S.J.; Nann, T. Graphene Quantum Dots. Part. Part. Syst. Charact. 2014, 31, 415-428. [CrossRef] 
21. Hutton, G.A.M.; Martindale, B.C.M.; Reisner, E. Carbon dots as photosensitisers for solar-driven catalysis. Chem. Soc. Rev. 2017, 46, 6111-6123. [CrossRef]

22. Zhao, Q.-L.; Zhang, Z.-L.; Huang, B.-H.; Peng, J.; Zhang, M.; Pang, D.-W. Facile preparation of low cytotoxicity fluorescent carbon nanocrystals by electrooxidation of graphite. Chem. Commun. 2008, 5116-5118. [CrossRef] [PubMed]

23. Li, M.; Yu, C.; Hu, C.; Yang, W.; Zhao, C.; Wang, S.; Zhang, M.; Zhao, J.; Wang, X.; Qiu, J. Solvothermal conversion of coal into nitrogen-doped carbon dots with singlet oxygen generation and high quantum yield. Chem. Eng. J. 2017, 320, 570-575. [CrossRef]

24. Wu, M.; Wang, Y.; Wu, W.; Hu, C.; Wang, X.; Zheng, J.; Li, Z.; Jiang, B.; Qiu, J. Preparation of functionalized water-soluble photoluminescent carbon quantum dots from petroleum coke. Carbon 2014, 78, 480-489. [CrossRef]

25. Jaiswal, A.; Ghosh, S.S.; Chattopadhyay, A. One step synthesis of C-dots by microwave mediated caramelization of poly(ethylene glycol). Chem. Commun. 2012, 48, 407-409. [CrossRef] [PubMed]

26. Zhu, C.; Zhai, J.; Dong, S. Bifunctional fluorescent carbon nanodots: Green synthesis via soy milk and application as metal-free electrocatalysts for oxygen reduction. Chem. Commun. 2012, 48, 9367-9369. [CrossRef] [PubMed]

27. Baker, S.N.; Baker, G.A. Luminescent Carbon Nanodots: Emergent Nanolights. Angew. Chem. Int. Ed. 2010, 49, 6726-6744. [CrossRef]

28. Kundu, S.; Patra, A. Nanoscale Strategies for Light Harvesting. Chem. Rev. 2016, 117, 712-757. [CrossRef]

29. Yan, X.; Cui, X.; Li, B.; Li, L.-S. Large, Solution-Processable Graphene Quantum Dots as Light Absorbers for Photovoltaics. Nano Lett. 2010, 10, 1869-1873. [CrossRef]

30. Liu, J.; Zhu, W.; Yu, S.; Yan, X. Three dimensional carbogenic dots $/ \mathrm{TiO}_{2}$ nanoheterojunctions with enhanced visible light-driven photocatalytic activity. Carbon 2014, 79, 369-379. [CrossRef]

31. Kim, H.; Kwon, W.; Choi, M.; Rhee, S.-W.; Yong, K. Photoelectrochemical Hydrogen Generation Using C-dot/ZnO Hierarchical Nanostructure as an Efficient Photoanode. J. Electrochem. Soc. 2015, 162, H366-H370. [CrossRef]

32. Wang, H.-X.; Xiao, J.; Yang, Z.; Tang, H.; Zhu, Z.-T.; Zhao, M.; Liu, Y.; Zhang, C.; Zhang, H.-L. Rational design of nitrogen and sulfur co-doped carbon dots for efficient photoelectrical conversion applications. J. Mater. Chem. A 2015, 3, 11287-11293. [CrossRef]

33. Wang, X.; Ling, D.; Wang, Y.; Long, H.; Sun, Y.; Shi, Y.; Chen, Y.; Jing, Y.; Sun, Y.; Dai, Y. N-doped graphene quantum dotsfunctionalized titanium dioxide nanofibers and their highly efficient photocurrent response. J. Mater. Res. 2014, 29, 1408-1416. [CrossRef]

34. Pan, D.; Jiao, J.; Li, Z.; Guo, Y.; Feng, C.; Liu, Y.; Wang, L.; Wu, M. Efficient Separation of Electron-Hole Pairs in Graphene Quantum Dots by $\mathrm{TiO}_{2}$ Heterojunctions for Dye Degradation. ACS Sustain. Chem. Eng. 2015, 3, 2405-2413. [CrossRef]

35. Wang, F.; Zhang, Y.; Liu, Y.; Wang, X.; Shen, M.; Lee, S.-T.; Kang, Z. Opto-electronic conversion logic behaviour through dynamic modulation of electron/energy transfer states at the $\mathrm{TiO}_{2}$-carbon quantum dot interface. Nanoscale 2013, 5, 1831-1835. [CrossRef]

36. Mihalache, I.; Radoi, A.; Mihaila, M.; Munteanu, C.; Marin, A.; Danila, M.; Kusko, M.; Kusko, C. Charge and energy transfer interplay in hybrid sensitized solar cells mediated by graphene quantum dots. Electrochim. Acta 2015, 153, 306-315. [CrossRef]

37. Sun, M.; Ma, X.; Chen, X.; Sun, Y.; Cui, X.; Lin, Y. A nanocomposite of carbon quantum dots and $\mathrm{TiO}_{2}$ nanotube arrays: Enhancing photoelectrochemical and photocatalytic properties. RSC Adv. 2014, 4, 1120-1127. [CrossRef]

38. Kokal, R.K.; Kumar, P.N.; Deepa, M.; Srivastava, A.K. Lead selenide quantum dots and carbon dots amplify solar conversion capability of a $\mathrm{TiO}_{2} / \mathrm{CdS}$ photoanode. J. Mater. Chem. A 2015, 3, 20715-20726. [CrossRef]

39. Zhang, H.; Wang, Y.; Liu, P.; Li, Y.; Yang, H.G.; An, T.; Wong, P.-K.; Wang, D.; Tang, Z.; Zhao, H. A fluorescent quenching performance enhancing principle for carbon nanodot-sensitized aqueous solar cells. Nano Energy 2015, 13, 124-130. [CrossRef]

40. Dang, Y.; Zhang, X.; Chen, X.; Kang, B.; Silva, S.R.P. Heterojunction solar cells with improved power conversion efficiency using graphene quantum dots. RSC Adv. 2016, 6, 110493-110498. [CrossRef]

41. Kwon, W.; Lee, G.; Do, S.; Joo, T.; Rhee, S.-W. Size-Controlled Soft-Template Synthesis of Carbon Nanodots toward Versatile Photoactive Materials. Small 2013, 10, 506-513. [CrossRef]

42. Li, F.; Kou, L.; Chen, W.; Wu, C.; Guo, T. Enhancing the short-circuit current and power conversion efficiency of polymer solar cells with graphene quantum dots derived from double-walled carbon nanotubes. NPG Asia Mater. 2013, 5, e60. [CrossRef]

43. Li, Y.; Hu, Y.; Zhao, Y.; Shi, G.; Deng, L.; Hou, Y.; Qu, L. An Electrochemical Avenue to Green-Luminescent Graphene Quantum Dots as Potential Electron-Acceptors for Photovoltaics. Adv. Mater. 2010, 23, 776-780. [CrossRef]

44. Anilkumar, P.; Wang, X.; Cao, L.; Sahu, S.; Liu, J.-H.; Wang, P.; Korch, K.; Ii, K.N.T.; Parenzan, A.; Sun, Y.-P. Toward quantitatively fluorescent carbon-based "quantum" dots. Nanoscale 2011, 3, 2023-2027. [CrossRef] [PubMed]

45. Cayuela, A.; Soriano, M.; Carrillocarrion, C.; Valcárcel, M. Semiconductor and carbon-based fluorescent nanodots: The need for consistency. Chem. Commun. 2016, 52, 1311-1326. [CrossRef] [PubMed]

46. Essner, J.B.; Baker, G.A. The emerging roles of carbon dots in solar photovoltaics: A critical review. Environ. Sci. Nano 2017, 4, 1216-1263. [CrossRef]

47. LeCroy, G.E.; Messina, F.; Sciortino, A.; Bunker, C.E.; Wang, P.; Fernando, K.A.S.; Sun, Y.-P. Characteristic Excitation Wavelength Dependence of Fluorescence Emissions in Carbon "Quantum" Dots. J. Phys. Chem. C 2017, 121, 28180-28186. [CrossRef]

48. Van Dam, B.; Nie, H.; Ju, B.; Marino, E.; Paulusse, J.M.J.; Schall, P.; Li, M.; Dohnalová, K. Carbon Dots: Excitation-Dependent Photoluminescence from Single-Carbon Dots. Small 2017, 13, 1702098. [CrossRef] [PubMed]

49. Teng, C.-Y.; Nguyen, B.-S.; Yeh, T.-F.; Lee, Y.-L.; Chen, S.-J.; Teng, H. Roles of nitrogen functionalities in enhancing the excitationindependent green-color photoluminescence of graphene oxide dots. Nanoscale 2017, 9, 8256-8265. [CrossRef] [PubMed] 
50. Shamsipur, M.; Barati, A.; Karami, S. Long-wavelength, multicolor, and white-light emitting carbon-based dots: Achievements made, challenges remaining, and applications. Carbon 2017, 124, 429-472. [CrossRef]

51. Wang, Z.; Yuan, F.; Li, X.; Li, Y.; Zhong, H.; Fanglong, Y.; Yang, S. 53\% Efficient Red Emissive Carbon Quantum Dots for High Color Rendering and Stable Warm White-Light-Emitting Diodes. Adv. Mater. 2017, 29, 1702910. [CrossRef] [PubMed]

52. Li, D.; Jing, P.; Sun, L.; An, Y.; Shan, X.; Lu, X.; Zhou, D.; Han, D.; Shen, D.; Zhai, Y.; et al. Near-Infrared Excitation/Emission and Multiphoton-Induced Fluorescence of Carbon Dots. Adv. Mater. 2018, 30, e1705913. [CrossRef] [PubMed]

53. Hasan, T.; Gonzalez-Rodriguez, R.; Ryan, C.; Faerber, N.; Coffer, J.L.; Naumov, A.V. Photo and Electroluminescence from Nitrogen Doped and Nitrogen Sulfur Codoped Graphene Quantum Dots. Adv. Funct. Mater. 2018, 28, 1804337. [CrossRef]

54. Song, Y.; Zhu, S.; Zhang, S.; Fu, Y.; Wang, L.; Zhao, X.; Yang, B. Investigation from chemical structure to photoluminescent mechanism: A type of carbon dots from the pyrolysis of citric acid and an amine. J. Mater. Chem. C 2015, 3, 5976-5984. [CrossRef]

55. Lu, S.; Xiao, G.; Sui, L.; Feng, T.; Yong, X.; Zhu, S.; Li, B.; Liu, Z.; Zou, B.; Jin, M.; et al. Piezochromic Carbon Dots with Two-photon Fluorescence. Angew. Chem. Int. Ed. 2017, 56, 6187-6191. [CrossRef]

56. Liu, C.; Xiao, G.; Yang, M.; Zou, B.; Zhang, Z.-L.; Pang, D.-W. Mechanofluorochromic Carbon Nanodots: Controllable PressureTriggered Blue- and Red-Shifted Photoluminescence. Angew. Chem. Int. Ed. 2017, 57, 1893-1897. [CrossRef]

57. Niu, X.; Li, Y.; Shu, H.; Wang, J. Revealing the underlying absorption and emission mechanism of nitrogen doped graphene quantum dots. Nanoscale 2016, 8, 19376-19382. [CrossRef]

58. Wang, C.; Xu, Z.; Cheng, H.; Lin, H.; Humphrey, M.G.; Zhang, C. A hydrothermal route to water-stable luminescent carbon dots as nanosensors for $\mathrm{pH}$ and temperature. Carbon 2015, 82, 87-95. [CrossRef]

59. Kalytchuk, S.; Poláková, K.; Wang, Y.; Froning, J.P.; Cepe, K.; Rogach, A.L.; Zbořil, R. Carbon Dot Nanothermometry: Intracellular Photoluminescence Lifetime Thermal Sensing. ACS Nano 2017, 11, 1432-1442. [CrossRef] [PubMed]

60. Alam, S.M.; Ananthanarayanan, A.; Huang, L.; Lim, K.H.; Chen, P. Revealing the tunable photoluminescence properties of graphene quantum dots. J. Mater. Chem. C 2014, 2, 6954-6960. [CrossRef]

61. Zhu, B.; Sun, S.; Wang, Y.; Deng, S.; Qian, G.; Wang, M.; Hu, A. Preparation of carbon nanodots from single chain polymeric nanoparticles and theoretical investigation of the photoluminescence mechanism. J. Mater. Chem. C 2013, 1, 580-586. [CrossRef]

62. Bao, L.; Zhang, Z.-L.; Tian, Z.-Q.; Zhang, L.; Liu, C.; Lin, Y.; Qi, B.; Pang, D.-W. Electrochemical Tuning of Luminescent Carbon Nanodots: From Preparation to Luminescence Mechanism. Adv. Mater. 2011, 23, 5801-5806. [CrossRef]

63. Zhang, X.; Wang, S.; Liu, M.; Yang, B.; Feng, L.; Ji, Y.; Tao, L.; Wei, Y. Size tunable fluorescent nano-graphite oxides: Preparation and cell imaging applications. Phys. Chem. Chem. Phys. 2013, 15, 19013-19018. [CrossRef]

64. Sun, X.; Liu, Z.; Welsher, K.; Robinson, J.T.; Goodwin, A.; Zaric, S.; Dai, H. Nano-graphene oxide for cellular imaging and drug delivery. Nano Res. 2008, 1, 203-212. [CrossRef]

65. Dong, Y.; Zhou, N.; Lin, X.; Jianpeng, L.; Chi, Y.; Chen, G. Extraction of Electrochemiluminescent Oxidized Carbon Quantum Dots from Activated Carbon. Chem. Mater. 2010, 22, 5895-5899. [CrossRef]

66. Liu, H.; Ye, T.; Mao, C. Fluorescent Carbon Nanoparticles Derived from Candle Soot. Angew. Chem. Int. Ed. 2007, 46, 6473-6475. [CrossRef]

67. Li, H.; He, X.; Kang, Z.; Huang, H.; Liu, Y.; Liu, J.; Lian, S.; Tsang, C.H.A.; Yang, X.; Lee, S.-T. Water-Soluble Fluorescent Carbon Quantum Dots and Photocatalyst Design. Angew. Chem. Int. Ed. 2010, 49, 4430-4434. [CrossRef]

68. Vinci, J.C.; Ferrer, I.M.; Seedhouse, S.J.; Bourdon, A.K.; Reynard, J.M.; Foster, B.A.; Bright, F.V.; Colón, L.A. Hidden Properties of Carbon Dots Revealed After HPLC Fractionation. J. Phys. Chem. Lett. 2012, 4, 239-243. [CrossRef] [PubMed]

69. Sun, Y.-P.; Zhou, B.; Lin, Y.; Wang, W.; Fernando, K.A.S.; Pathak, P.; Meziani, M.J.; Harruff, B.A.; Wang, X.; Wang, H.; et al. Quantum-Sized Carbon Dots for Bright and Colorful Photoluminescence. J. Am. Chem. Soc. 2006, 128, 7756-7757. [CrossRef] [PubMed]

70. Wang, X.; Cao, L.; Yang, S.T.; Lu, F.S.; Meziani, M.J.; Tian, L.L.; Sun, K.W.; Bloodgood, M.A.; Sun, Y.P. Bandgap-Like Strong Fluorescence in Functionalized Carbon Nanoparticles. Angew. Chem. Int. Ed. 2010, 49, 5310-5314. [CrossRef] [PubMed]

71. Tetsuka, H.; Asahi, R.; Nagoya, A.; Okamoto, K.; Tajima, I.; Ohta, R.; Okamoto, A. Optically Tunable Amino-Functionalized Graphene Quantum Dots. Adv. Mater. 2012, 24, 5333-5338. [CrossRef] [PubMed]

72. Tetsuka, H.; Nagoya, A.; Fukusumi, T.; Matsui, T. Molecularly Designed, Nitrogen-Functionalized Graphene Quantum Dots for Optoelectronic Devices. Adv. Mater. 2016, 28, 4632-4638. [CrossRef] [PubMed]

73. Zheng, H.; Wang, Q.; Long, Y.; Zhang, H.; Huang, X.; Zhu, R. Enhancing the luminescence of carbon dots with a reduction pathway. Chem. Commun. 2011, 47, 10650-10652. [CrossRef] [PubMed]

74. Zhang, W.; Liu, Y.; Meng, X.; Ding, T.; Xu, Y.; Xu, H.; Ren, Y.; Liu, B.; Huang, J.; Yang, J.; et al. Graphenol defects induced blue emission enhancement in chemically reduced graphene quantum dots. Phys. Chem. Chem. Phys. 2015, 17, 22361-22366. [CrossRef]

75. Mandal, B.; Sarkar, S.; Sarkar, P. Theoretical Studies on Understanding the Feasibility of Porphyrin-Sensitized Graphene Quantum Dot Solar Cell. J. Phys. Chem. C 2015, 119, 3400-3407. [CrossRef]

76. Rigodanza, F.; Dordevich, L.; Arcudi, F.; Prato, M. Customizing the Electrochemical Properties of Carbon Nanodots by Using Quinones in Bottom-Up Synthesis. Angew. Chem. Int. Ed. 2018, 57, 5062-5067. [CrossRef]

77. Yang, G.; Wu, C.; Luo, X.; Liu, X.; Gao, Y.; Wu, P.; Cai, C.; Saavedra, S.S. Exploring the Emissive States of Heteroatom-Doped Graphene Quantum Dots. J. Phys. Chem. C 2018, 122, 6483-6492. [CrossRef]

78. Holá, K.; Sudolská, M.; Kalytchuk, S.; Nachtigallová, D.; Rogach, A.L.; Otyepka, M.; Zbořil, R. Graphitic Nitrogen Triggers Red Fluorescence in Carbon Dots. ACS Nano 2017, 11, 12402-12410. [CrossRef] 
79. Fernando, K.A.S.; Sahu, S.; Liu, Y.; Lewis, W.K.; Guliants, E.A.; Jafariyan, A.; Wang, P.; Bunker, C.E.; Sun, Y.-P. Carbon Quantum Dots and Applications in Photocatalytic Energy Conversion. ACS Appl. Mater. Interfaces 2015, 7, 8363-8376. [CrossRef]

80. Günes, S.; Neugebauer, H.; Sariciftci, N.S. Conjugated Polymer-Based Organic Solar Cells. Chem. Rev. 2007, 107, 1324-1338. [CrossRef]

81. Yan, L.; Li, Y.; Yang, Y.; Liu, X.; Chen, Y.; Xu, B. P3HT/Dodecylamine Functioned Carbon Microspheres Composite Films for Polymer Solar Cells. Full Nanotub. Carbon Nanostruct. 2014, 23, 549-556. [CrossRef]

82. Feng, X.; Zhao, Y.; Yan, L.; Zhang, Y.; He, Y.; Yang, Y.; Liu, X. Low-Temperature Hydrothermal Synthesis of Green Luminescent Carbon Quantum Dots (CQD), and Optical Properties of Blends of the CQD with Poly(3-hexylthiophene). J. Electron. Mater. 2015, 44, 3436-3443. [CrossRef]

83. Bin Yang, H.; Dong, Y.Q.; Wang, X.; Khoo, S.Y.; Liu, B. Cesium Carbonate Functionalized Graphene Quantum Dots as Stable Electron-Selective Layer for Improvement of Inverted Polymer Solar Cells. ACS Appl. Mater. Interfaces 2013, 6, 1092-1099. [CrossRef]

84. Bin Yang, H.; Dong, Y.Q.; Wang, X.; Khoo, S.Y.; Liu, B.; Li, C.M. Graphene quantum dots-incorporated cathode buffer for improvement of inverted polymer solar cells. Sol. Energy Mater. Sol. Cells 2013, 117, 214-218. [CrossRef]

85. Wang, F.; Chen, Y.-H.; Liu, C.-Y.; Ma, D.-G. White light-emitting devices based on carbon dots' electroluminescence. Chem. Commun. 2011, 47, 3502-3504. [CrossRef]

86. Xie, C.; Nie, B.; Zeng, L.; Liang, F.-X.; Wang, M.-Z.; Luo, L.; Feng, M.; Yu, Y.; Wu, C.-Y.; Wu, Y.; et al. Core-Shell Heterojunction of Silicon Nanowire Arrays and Carbon Quantum Dots for Photovoltaic Devices and Self-Driven Photodetectors. ACS Nano 2014, 8, 4015-4022. [CrossRef] [PubMed]

87. Gao, P.; Ding, K.; Wang, Y.; Ruan, K.; Diao, S.; Zhang, Q.; Sun, B.; Jie, J. Crystalline Si/Graphene Quantum Dots Heterojunction Solar Cells. J. Phys. Chem. C 2014, 118, 5164-5171. [CrossRef]

88. Zhang, X.; Liu, C.; Li, Z.; Guo, J.; Shen, L.; Guo, W.; Zhang, L.; Ruan, S.; Long, Y. An easily prepared carbon quantum dots and employment for inverted organic photovoltaic devices. Chem. Eng. J. 2017, 315, 621-629. [CrossRef]

89. Kim, J.K.; Park, M.J.; Kim, S.J.; Wang, N.H.; Cho, S.P.; Bae, S.; Park, J.H.; Hong, B.H. Balancing Light Absorptivity and Carrier Conductivity of Graphene Quantum Dots for High-Efficiency Bulk Heterojunction Solar Cells. ACS Nano 2013, 7, 7207-7212. [CrossRef]

90. Gupta, V.; Chaudhary, N.; Srivastava, R.; Sharma, G.D.; Bhardwaj, R.; Chand, S. Luminscent Graphene Quantum Dots for Organic Photovoltaic Devices. J. Am. Chem. Soc. 2011, 133, 9960-9963. [CrossRef]

91. Privitera, A.; Righetto, M.; Mosconi, D.; Lorandi, F.; Isse, A.A.; Moretto, A.; Bozio, R.; Ferrante, C.; Franco, L. Boosting carbon quantum dots/fullerene electron transfer via surface group engineering. Phys. Chem. Chem. Phys. 2016, 18, 31286-31295. [CrossRef] [PubMed]

92. Yu, P.; Wen, X.; Toh, Y.-R.; Lee, Y.-C.; Huang, K.-Y.; Huang, S.; Shrestha, S.; Conibeer, G.; Tang, J. Efficient electron transfer in carbon nanodot-graphene oxide nanocomposites. J. Mater. Chem. C 2014, 2, 2894. [CrossRef]

93. Wang, X.; Cao, L.; Lu, F.; Meziani, M.J.; Li, H.; Qi, G.; Zhou, B.; Harruff, B.A.; Kermarrec, F.; Sun, Y.-P. Photoinduced electron transfers with carbon dots. Chem. Commun. 2009, 3774-3776. [CrossRef] [PubMed]

94. Mondal, S.; Seth, S.K.; Gupta, P.; Purkayastha, P. Ultrafast Photoinduced Electron Transfer between Carbon Nanoparticles and Cyclometalated Rhodium and Iridium Complexes. J. Phys. Chem. C 2015, 119, 25122-25128. [CrossRef]

95. Ding, Z.; Hao, Z.; Meng, B.; Xie, Z.; Liu, J.; Dai, L. Few-layered graphene quantum dots as efficient hole-extraction layer for high-performance polymer solar cells. Nano Energy 2015, 15, 186-192. [CrossRef]

96. Li, M.; Ni, W.; Kan, B.; Wan, X.; Zhang, L.; Zhang, Q.; Long, G.; Zuo, Y.; Chen, Y. Graphene quantum dots as the hole transport layer material for high-performance organic solar cells. Phys. Chem. Chem. Phys. 2013, 15, 18973-18978. [CrossRef]

97. Lim, H.C.; Min, S.H.; Lee, E.; Jang, J.; Kim, S.H.; Hong, J.-I. Self-Assembled Poly(3,4-ethylene dioxythiophene): Poly(styrenesulfonate) /Graphene Quantum Dot Organogels for Efficient Charge Transport in Photovoltaic Devices. ACS Appl. Mater. Interfaces 2015, 7, 11069-11073. [CrossRef]

98. Samal, M.; Barange, N.; Ko, D.-H.; Yun, K. Graphene Quantum Rings Doped PEDOT:PSS Based Composite Layer for Efficient Performance of Optoelectronic Devices. J. Phys. Chem. C 2015, 119, 19619-19627. [CrossRef]

99. Wang, Y.; Yan, L.; Ji, G.; Wang, C.; Gu, H.; Luo, Q.; Chen, Q.; Chen, L.; Yang, Y.; Ma, C.-Q.; et al. Synthesis of N,S-Doped Carbon Quantum Dots for Use in Organic Solar Cells as the ZnO Modifier to Eliminate the Light-Soaking Effect. ACS Appl. Mater. Interfaces 2019, 11, 2243-2253. [CrossRef]

100. Li, Z.; Zhang, X.; Liu, C.; Guo, J.; Cui, H.; Shen, L.; Guo, W. Toward Efficient Carbon-Dots-Based Electron-Extraction Layer Through Surface Charge Engineering. ACS Appl. Mater. Interfaces 2018, 10, 40255-40264. [CrossRef]

101. Lim, H.; Liu, Y.; Kim, H.Y.; Son, D.I. Facile synthesis and characterization of carbon quantum dots and photovoltaic applications. Thin Solid Films 2018, 660, 672-677. [CrossRef]

102. Shalini, S.; Balasundaraprabhu, R.; Kumar, T.S.; Prabavathy, N.; Senthilarasu, S.; Prasanna, S. Status and outlook of sensitizers/dyes used in dye sensitized solar cells (DSSC): A review. Int. J. Energy Res. 2016, 40, 1303-1320. [CrossRef]

103. Murakami, T.N.; Grätzel, M. Counter electrodes for DSC: Application of functional materials as catalysts. Inorg. Chim. Acta 2008, 361, 572-580. [CrossRef]

104. Jeon, S.S.; Kim, C.; Ko, J.; Im, S.S. Spherical polypyrrole nanoparticles as a highly efficient counter electrode for dye-sensitized solar cells. J. Mater. Chem. 2011, 21, 8146-8151. [CrossRef] 
105. Zang, J.; Li, C.M.; Bao, S.-J.; Cui, X.; Bao, Q.; Sun, C.Q. Template-Free Electrochemical Synthesis of Superhydrophilic Polypyrrole Nanofiber Network. Macromolecules 2008, 41, 7053-7057. [CrossRef]

106. Wu, J.; Li, Q.; Fan, L.; Lan, Z.; Li, P.; Lin, J.; Hao, S. High-performance polypyrrole nanoparticles counter electrode for dyesensitized solar cells. J. Power Sources 2008, 181, 172-176. [CrossRef]

107. Skompska, M. Hybrid conjugated polymer/semiconductor photovoltaic cells. Synth. Met. 2010, 160, 1-15. [CrossRef]

108. Lu, M.-N.; Chang, C.-Y.; Wei, T.-C.; Lin, J.-Y. Recent Development of Graphene-Based Cathode Materials for Dye-Sensitized Solar Cells. J. Nanomater. 2016, 2016, 1-21. [CrossRef]

109. Dou, D.; Duan, J.; Zhao, Y.; He, B.; Tang, Q. Cubic carbon quantum dots for light-harvesters in mesoscopic solar cells. Electrochim. Acta 2018, 275, 275-280. [CrossRef]

110. Efa, M.T.; Imae, T. Effects of carbon dots on ZnO nanoparticle-based dye-sensitized solar cells. Electrochim. Acta 2019, 303, 204-210. [CrossRef]

111. Meng, Y.; Zhang, Y.; Sun, W.; Wang, M.; He, B.; Chen, H.; Tang, Q. Biomass converted carbon quantum dots for all-weather solar cells. Electrochim. Acta 2017, 257, 259-266. [CrossRef]

112. Briscoe, J.; Marinovic, A.; Sevilla, M.; Dunn, S.; Titirici, M. Biomass-Derived Carbon Quantum Dot Sensitizers for Solid-State Nanostructured Solar Cells. Angew. Chem. Int. Ed. 2015, 54, 4463-4468. [CrossRef] [PubMed]

113. Liang, Z.; Zeng, L.; Cao, X.; Wang, Q.; Wang, X.; Sun, R. Sustainable carbon quantum dots from forestry and agricultural biomass with amplified photoluminescence by simple NH4OH passivation. J. Mater. Chem. C 2014, 2, 9760-9766. [CrossRef]

114. Qi, H.; Teng, M.; Liu, M.; Liu, S.; Li, J.; Yu, H.; Teng, C.; Huang, Z.; Liu, H.; Shao, Q.; et al. Biomass-derived nitrogen-doped carbon quantum dots: Highly selective fluorescent probe for detecting Fe3+ ions and tetracyclines. J. Colloid Interface Sci. 2019, 539, 332-341. [CrossRef]

115. Zhao, Y.; Duan, J.; He, B.; Jiao, Z.; Tang, Q. Improved charge extraction with N-doped carbon quantum dots in dye-sensitized solar cells. Electrochim. Acta 2018, 282, 255-262. [CrossRef]

116. Riaz, R.; Ali, M.; Maiyalagan, T.; Anjum, A.S.; Lee, S.Y.; Ko, M.J.; Jeong, S.H. Dye-sensitized solar cell (DSSC) coated with energy down shift layer of nitrogen-doped carbon quantum dots (N-CQDs) for enhanced current density and stability. Appl. Surf. Sci. 2019, 483, 425-431. [CrossRef]

117. Chen, L.; Guo, C.X.; Zhang, Q.; Lei, Y.; Xie, J.; Ee, S.; Guai, G.; Song, Q.; Li, C.M. Graphene Quantum-Dot-Doped Polypyrrole Counter Electrode for High-Performance Dye-Sensitized Solar Cells. ACS Appl. Mater. Interfaces 2013, 5, 2047-2052. [CrossRef]

118. Lee, K.; Cho, S.; Kim, M.; Kim, J.; Ryu, J.; Shin, K.-Y.; Jang, J. Highly porous nanostructured polyaniline/carbon nanodots as efficient counter electrodes for Pt-free dye-sensitized solar cells. J. Mater. Chem. A 2015, 3, 19018-19026. [CrossRef]

119. Dinari, M.; Momeni, M.M.; Goudarzirad, M. Dye-sensitized solar cells based on nanocomposite of polyaniline/graphene quantum dots. J. Mater. Sci. 2016, 51, 2964-2971. [CrossRef]

120. Wang, C.-C.; Lu, S.-Y. Carbon black-derived graphene quantum dots composited with carbon aerogel as a highly efficient and stable reduction catalyst for the iodide/tri-iodide couple. Nanoscale 2015, 7, 1209-1215. [CrossRef]

121. Duan, J.; Zhao, Y.; He, B.; Tang, Q. Efficiency enhancement of bifacial dye-sensitized solar cells through bi-tandem carbon quantum dots tailored transparent counter electrodes. Electrochim. Acta 2018, 278, 204-209. [CrossRef]

122. Lee, J.; Ko, S.-J.; Lee, H.; Huang, J.; Zhu, Z.; Seifrid, M.; Vollbrecht, J.; Brus, V.V.; Karki, A.; Wang, H.; et al. Side-Chain Engineering of Nonfullerene Acceptors for Near-Infrared Organic Photodetectors and Photovoltaics. ACS Energy Lett. 2019, 4, 1401-1409. [CrossRef]

123. Karki, A.; Vollbrecht, J.; Gillett, A.J.; Selter, P.; Lee, J.; Peng, Z.; Schopp, N.; Dixon, A.L.; Schrock, M.; Nádaždy, V.; et al. Unifying Charge Generation, Recombination, and Extraction in Low-Offset Non-Fullerene Acceptor Organic Solar Cells. Adv. Energy Mater. 2020, 10, 2001203. [CrossRef]

124. Brus, V.V.; Lee, H.K.; Proctor, C.M.; Ford, M.; Liu, X.; Burgers, M.A.; Lee, J.; Bazan, G.C.; Nguyen, T.-Q. Balance Between Light Absorption and Recombination Losses in Solution-Processed Small Molecule Solar Cells with Normal or Inverted Structures. Adv. Energy Mater. 2018, 8, 1801807. [CrossRef]

125. Ji, J.; Zhou, H.; Eom, Y.K.; Kim, C.H.; Kim, H.K. Dye-Sensitized Solar Cells: 14.2\% Efficiency Dye-Sensitized Solar Cells by Co-sensitizing Novel Thieno[3,2-b]indole-Based Organic Dyes with a Promising Porphyrin Sensitizer. Adv. Energy Mater. 2020, 10, 2000124. [CrossRef] 